\title{
Effect of lauric acid and coconut oil on ruminal fermentation, digestion, ammonia losses from manure, and milk fatty acid composition in lactating cows
}

\author{
A. N. Hristov, ${ }^{, 1,2}$ M. Vander Pol, ${ }^{*}$ M. Agle, ${ }^{*}$ S. Zaman, ${ }^{*}$ C. Schneider, ${ }^{*}$ P. Ndegwa, $\dagger$ V. K. Vaddella, $\dagger$ \\ K. Johnson, $\ddagger$ K. J. Shingfield,§ and S. K. R. Karnati\# \\ *Department of Animal and Veterinary Science, University of Idaho, Moscow 83844 \\ †Biological Systems Engineering Department, Washington State University, Pullman 99164 \\ $\ddagger$ Department of Animal Science, Washington State University, Pullman 99164 \\ §Animal Production Research, MTT Agrifood Research Finland, FI 31600, Jokioinen, Finland \\ \#Department of Animal Sciences, The Ohio State University, Columbus 43210
}

\begin{abstract}
This experiment (replicated $3 \times 3$ Latin square design) was conducted to investigate the effects of lauric acid (LA) or coconut oil (CO) on ruminal fermentation, nutrient digestibility, ammonia losses from manure, and milk fatty acid (FA) composition in lactating cows. Treatments consisted of intraruminal doses of $240 \mathrm{~g}$ of stearic acid/d (SA; control), $240 \mathrm{~g}$ of LA/d, or $530 \mathrm{~g}$ of $\mathrm{CO} / \mathrm{d}$ administered once daily, before feeding. Between periods, cows were inoculated with ruminal contents from donor cows and allowed a 7-d recovery period. Treatment did not affect dry matter intake, milk yield, or milk composition. Ruminal $\mathrm{pH}$ was slightly increased by $\mathrm{CO}$ compared with the other treatments, whereas LA and $\mathrm{CO}$ decreased ruminal ammonia concentration compared with SA. Both LA and CO decreased protozoal counts by $80 \%$ or more compared with SA. Methane production rate in the rumen was reduced by CO compared with LA and SA, with no differences between LA and SA. Treatments had no effect on total tract apparent dry matter, organic matter, $\mathrm{N}$, and neutral detergent fiber digestibility coefficients or on cumulative (15 d) in vitro ammonia losses from manure. Compared with SA, LA and CO increased milk fat 12:0, cis-9 12:1, and trans-9 12:1 content and decreased 6:0, 8:0, 10:0, cis-9 10:1, 16:0, 18:0, cis 18:1, total 18:2, 18:3 n-3 and total polyunsaturated FA concentrations. Administration of LA and 14:0 (as CO) in the rumen were apparently transferred into milk fat with a mean efficiency of 18 and 15\%, respectively. In conclusion, current data confirmed that LA and CO exhibit strong antiprotozoal activity when dosed intraruminally, an
\end{abstract}

Received May 14, 2009.

Accepted June 17, 2009.

${ }^{1}$ Current address: Department of Dairy and Animal Science, The Pennsylvania State University, University Park 16802.

${ }^{2}$ Corresponding author: anh13@psu.edu effect that is accompanied by decreases in ammonia concentration and, for $\mathrm{CO}$, lowered methane production. Administration of LA and $\mathrm{CO}$ in the rumen also altered milk FA composition.

Key words: lauric acid, myristic acid, coconut oil, protozoa

\section{INTRODUCTION}

Dietary fats are potent modifiers of ruminal fermentation and may offer a nutritional strategy to reduce protozoal predation and intraruminal recycling of bacterial protein, thus improving the efficiency of dietary protein utilization and mitigating $\mathrm{N}$ losses in the ruminant animal (Hristov and Jouany, 2005). Long-chain unsaturated fatty acids (FA) typically suppress the activity of fibrolytic bacteria in the rumen (Palmquist and Jenkins, 1980). Metabolism of C18 FA has been extensively investigated because of the interest in enhancing the concentrations of bioactive lipids in milk with the potential to improve long-term human health, including cis-9, trans-11 conjugated linoleic acid (CLA), cis-9 18:1, and 18:3 n-3 (Jenkins and McGuire, 2006; Shingfield et al., 2008c). Medium-chain saturated FA (MCFA) are also known to modify ruminal fermentation (Blaxter and Czerkawski, 1966; Henderson, 1973), effects that are of increasing interest with regards to mitigating greenhouse gas emissions from ruminant livestock production (Machmüller, 2006). Mediumchain FA such as lauric (LA) and myristic (MA) acids exhibit potent antiprotozoal properties and, by association, have an array of effects on formation of fermentation end products and methane production in the rumen (Sutton et al., 1983; Hristov et al., 2004a,b; Soliva et al., 2004). Suppression of ruminal methane production by LA, MA, or coconut oil (CO) as a source of these MCFA (CO contains 45\% LA and 18\% MA; CRC, 1988) is known to be mediated via a reduction in ruminal protozoal numbers and also through direct 
inhibition of rumen methanogens (Dohme et al., 1999, 2001). Thus, supplementation of cattle diets with MCFA or CO (as a source of LA and MA) may be a practically feasible method of reducing enteric methane emission from ruminants and the environmental impact of livestock operations. Reductions in ruminal ammonia concentration in response to LA (Machmüller et al., 2002; Hristov et al., 2004a) or CO (Dohme et al., 1999) may also reflect reduced proteolysis and deamination or more efficient conversion of ruminal ammonia into microbial protein, leading to an overall improvement in the efficiency of dietary $\mathrm{N}$ utilization. Because urinary urea is the primary source of ammonia emitted from cattle manure (Bussink and Oenema, 1998), formulation of diets that decrease urinary urea excretion are also central to nutritional strategies for the mitigation of ammonia emissions from manure.

Inclusion of LA (or CO) in the diet of dairy cows may also increase LA and MA content of milk fat (Steele and Moore, 1968; Rindsig and Schultz, 1974; Dohme et al., 2004). Clinical and epidemiological studies have provided evidence that when consumed in excess, LA, $\mathrm{MA}$, and 16:0 in the human diet increase cardiovascular disease (CVD) risk and may also reduce insulin sensitivity which is a key factor in the development of the metabolic syndrome (Shingfield et al., 2008c). However, even though the constituent MCFA in CO may increase total plasma cholesterol, a high proportion of this is caused by elevated high-density lipoprotein (HDL) cholesterol concentrations. A meta-analysis of 60 human subject trials concluded that LA had a more favorable effect on total:HDL cholesterol ratio than any other FA studied (Mensink et al., 2003), indicating that ruminant milk containing higher proportions of MCFA may offer potential benefits with respect to human nutrition and health.

In light of the diverse biological activity of MCFA in ruminants, the current study examined the impact of ruminal administration of LA and CO on rumen fermentation characteristics and methane production, nutrient digestibility, urinary $\mathrm{N}$ losses, ammonia emitting potential of manure, and milk FA composition. The underlying experimental hypotheses being tested were that LA and $\mathrm{CO}$ would reduce methane production in the rumen, improve the efficiency of dietary $\mathrm{N}$ utilization, and enhance milk fat LA and MA content.

\section{MATERIALS AND METHODS}

Animals involved in this study were cared for according to the guidelines of the University of Idaho Animal Care and Use Committee. The committee reviewed and approved the experiment and all procedures carried out in the study.

\section{Animals and Experimental Design}

Six multiparous Holstein cows $(682 \pm 43.9 \mathrm{~kg}$ BW; $128 \pm 25.2$ DIM at the start of the trial) fitted with 10$\mathrm{cm}$ ruminal cannulas (Bar Diamond, Parma, ID) were used. Cows were randomly assigned to experimental treatments in a replicated $3 \times 3$ Latin square design. Treatments were control (SA; $240 \mathrm{~g}$ of stearic acid/cow per d), LA (240 g of lauric acid/cow per d), and CO (530 g of coconut oil/cow per d). Lauric and stearic acids were from KIC Chemicals, Inc. (New Paltz, NY) and $\mathrm{CO}$ was food-grade 76 degree coconut oil (GloryBee Foods Inc., Eugene, OR) declared as containing $46 \mathrm{~g}$ of $\mathrm{LA} / 100 \mathrm{~g}$ of FA. Other major FA in CO were (per 100 $\mathrm{g}$ of FA): MA, $20 \mathrm{~g}$; 16:0, $11 \mathrm{~g}$; monounsaturated FA, 7 g; 8:0, 6.1 g; 10:0, $5.5 \mathrm{~g} ; 18: 0,3 \mathrm{~g}$; and polyunsaturated FA (PUFA), 2 g. The application level of LA (and SA) was chosen based on previous studies (Hristov et al., 2004b), whereas the dose of CO was administered to provide approximately $240 \mathrm{~g}$ of LA. Stearic acid was used as a control treatment because it has minimal effects on ruminal fermentation (Hristov et al., 2004a). Treatments were applied as a pulse dose, once a day (immediately before morning feeding) directly into the rumen via the cannula by mixing with approximately $5 \mathrm{~kg}$ of whole ruminal contents. The basal diet was fed as a TMR (Table 1) and formulated (NRC, 2001) to meet or exceed the nutrient requirements (at $25 \mathrm{~kg}$ of DMI/d) of a Holstein cow yielding $35 \mathrm{~kg}$ of milk/d containing $3.70 \%$ milk fat and $3.20 \%$ true protein. Cows were offered the daily ration as equal meals at 07:00 and 18:00 h. Diets were fed ad libitum in amounts resulting in 5\% refusals. Each experimental period was comprised of a 14-d treatment adaptation and $7 \mathrm{~d}$ for sampling. On the last day of periods 1 and 2, all cows were transfaunated with approximately $10 \mathrm{~kg}$ of whole ruminal contents/cow from donor cows fed the same basal diet (not supplemented with FA). Following a 7-d refaunation period (during which the cows were moved with the rest of the herd), the cows were assigned to new treatments. During the adaptation periods, the cows were housed in box stalls and then moved to tie stalls for the duration of the sampling period. Cows had continuous access to fresh water and did not receive recombinant bovine somatotropin during the trial.

\section{Sampling and Measurements}

Samples of forage, TMR, and refusals were collected daily and concentrate feeds were sampled weekly. Feed samples were composited and analyzed for DM $\left(65^{\circ} \mathrm{C}\right.$ in a forced-air oven, dried to a constant weight) and ash/OM (AOAC, 2000), N (Foley et al., 2006), NDF (Van Soest et al., 1991), and starch (starch assay kit, 
Table 1. Ingredient and chemical composition of the basal diet fed in the trial

\begin{tabular}{|c|c|}
\hline Ingredient & $\%$ of DM \\
\hline Alfalfa hay ${ }^{1}$ & 14.0 \\
\hline Alfalfa silage ${ }^{2}$ & 25.1 \\
\hline Barley silage $^{3}$ & 13.7 \\
\hline Ground peas $^{4}$ & 19.2 \\
\hline Corn grain, ground & 8.0 \\
\hline Barley grain, rolled & 7.0 \\
\hline Corn dry distillers grain with solubles & 4.5 \\
\hline Cottonseed, whole with lint & 4.4 \\
\hline Mineral/vitamin/fat premix ${ }^{5}$ & 4.1 \\
\hline \multicolumn{2}{|l|}{ Composition, ${ }^{6} \%$ of DM } \\
\hline Crude protein & 15.9 \\
\hline $\mathrm{NDF}$ & 32.2 \\
\hline $\mathrm{ADF}$ & 24.8 \\
\hline $\mathrm{NE}_{\mathrm{L}},{ }_{7}^{7} \mathrm{Mcal} / \mathrm{kg}$ & 1.54 \\
\hline $\mathrm{NFC}^{7}$ & 41.7 \\
\hline $\mathrm{Ca}$ & 1.00 \\
\hline $\mathrm{P}$ & 0.38 \\
\hline
\end{tabular}

${ }^{1}$ Alfalfa hay contained (as \% of DM) $41 \% \mathrm{NDF}$ and $20 \% \mathrm{CP}$.

${ }^{2}$ Alfalfa silage (baleage) was $33 \% \mathrm{DM}$ and contained (as \% of DM) $43 \% \mathrm{NDF}$ and $16 \% \mathrm{CP}$.

${ }^{3}$ Barley silage (baleage) was $37 \% \mathrm{DM}$ and contained (as \% of DM) $61 \%$ $\mathrm{NDF}$ and $6 \% \mathrm{CP}$.

${ }^{4}$ Peas were US No. 1 Feed peas (Federal Grain Inspection Service, Moscow, ID) and contained $11 \%$ moisture and (\%, DM basis) CP, 25.3; starch, 48.0; amylase NDF, 9.2; ADF, 5.1; lignin, 0.3; fat, 1.0; ash, 2.1; $\mathrm{Ca}, 0.08 ; \mathrm{P}, 0.41$; and estimated $\mathrm{NE}_{\mathrm{L}}, 1.97 \mathrm{Mcal} / \mathrm{kg}$; total digestible nutrients, 86; and NFC, 67.0 (DairyOne, Ithaca, NY).

${ }^{5}$ Land O'Lakes (St. Paul, MN). The premix contained (\%, as-is basis) fat nugget, 42; calcium carbonate, 17.2; sodium sesquicarbonate, 7.8; wheat middlings, 7.5; corn grain, ground, 7.1; salt, 6.3; MetaSmart (Adisseo USA Inc., Alpharetta, GA), 5.1; magnesium oxide, 4.5; trace mineral/vitamin premix, 2.5. Composition (DM basis): fat, 18.9\%; Ca, 7.4\%; Na, 5.1\%; P, 0.23\%; Mg, 2.77\%, S, 0.21\%; Cu, 488 mg/kg; Zn, $2,454 \mathrm{mg} / \mathrm{kg} ; \mathrm{Mn}, 77.1 \mathrm{mg} / \mathrm{kg} ; \mathrm{Fe}, 464 \mathrm{mg} / \mathrm{kg}$; Se, $8.15 \mathrm{mg} / \mathrm{kg}$; Co, 2.3 $\mathrm{mg} / \mathrm{kg}$; I, $21.0 \mathrm{mg} / \mathrm{kg}$; vitamin A, 148,016 IU $/ \mathrm{kg}$; vitamin D, 23,122 $\mathrm{IU} / \mathrm{kg}$; and vitamin E, $960 \mathrm{IU} / \mathrm{kg}$.

${ }^{6}$ Analyzed (except $\mathrm{NE}_{\mathrm{L}}$ and $\mathrm{NFC}$ ).

${ }^{7}$ Estimated based on NRC (2001).

Megazyme International Ireland Ltd., Wicklow, Ireland; McCleary et al., 1994). A heat-stable $\alpha$-amylase was used in the NDF analysis. Sodium sulfite was not used in the analysis and NDF was expressed inclusive of residual ash. Composite TMR samples were also analyzed for acid-insoluble ash (AIA; Van Keulen and Young, 1977).

Ruminal ammonia $\mathrm{N}$ was labeled using a pulse dose of $2 \mathrm{~g}$ of 99 atom percent excess ${ }^{15} \mathrm{NH}_{4} \mathrm{Cl} /$ cow (Cambridge Isotope Laboratories, Inc., Andover, MA) dissolved in 5 L of McDougall's buffer (McDougall, 1948). Rumen evacuations were performed before morning feeding on d 17 of each period. Total rumen contents were weighed and thoroughly mixed. A background sample of rumen digesta was collected and ${ }^{15} \mathrm{NH}_{4} \mathrm{Cl}$ and Cr-EDTA (1 L/ cow, equivalent of $2.5 \mathrm{~g}$ of $\mathrm{Cr} / \mathrm{cow}$; Udén et al., 1980) were added. After thorough mixing with ruminal contents, a 0-h sample was collected and evacuated digesta was returned into the rumen. Chromium-EDTA was used as a ruminal liquid passage rate marker, because previous studies have established that ruminal administration of Cr-EDTA has no effect on milk fat composition (Shingfield et al., 2008b).

Whole ruminal contents samples were collected at 0 , $1,2,4,6,8,10,14,18$, and $24 \mathrm{~h}$ following the morning feeding on d 17 of each experimental period. Ruminal samples were collected from 4 locations in the rumen and the reticulum (approximately $250 \mathrm{~g}$ each), composited, and analyzed for DM and ${ }^{15} \mathrm{~N}$ enrichment of the ammonia $\mathrm{N}$ and bacterial and whole ruminal contents (WRC) NAN. Aliquots of rumen samples were filtered through cheesecloth, centrifuged $(20,000 \times g$ for 15 min at $4^{\circ} \mathrm{C}$ ) and the supernatant fluid was analyzed for $\mathrm{Cr}$ (Iris ICP atomic emission spectrophotometer, Thermo Jarrell Ash Corp., Franklin, MA). Fractional outflow rate of the ruminal fluid was calculated as lntransformed $\mathrm{Cr}$ concentrations plotted against time. Subsamples of the rumen cheesecloth filtrates were immediately analyzed for $\mathrm{pH}$, and processed for analyses of ammonia and total free amino acids (TFAA; Hristov et al., 1999), VFA (Foley et al., 2006), and polysaccharide-degrading (carboxymethylcellulase, amylase, and xylanase) activities (Hristov et al., 1998). Individual ruminal samples were analyzed for ammonia and $\mathrm{pH}$; the remaining analyses were performed on composite (by cow and treatment) samples. Samples for protozoal enumeration were preserved (Hristov et al., 2001) and counted according to standard procedures (Dehority, 1993). Generic distribution of protozoa was determined from the total number of cells of each genera counted in 100 fields using the Sedgewick-Rafter chamber (Hausser Scientific, Horsham, PA). One ruminal sample for protozoal counts was also collected before the morning feeding on $\mathrm{d} 1$ of the experiment and on the last day of each refaunation period, corresponding to $\mathrm{d} 1$ of periods 2 and 3.

Methane production in the rumen was measured utilizing the sulfur hexafluoride $\left(\mathrm{SF}_{6}\right)$ tracer technique (Johnson et al., 1994). The $\mathrm{SF}_{6}$ permeation tubes were prepared by K. Johnson (Washington State University, Pullman). They were placed in the reticulum of the cows on $\mathrm{d} 1$ of the experiment and remained there for the duration of the entire study. Gas samples for methane analysis were collected directly from the rumen through modified rumen cannula lids. In brief, the lids were fitted with Teflon tubing that had a septum and a valve on one end and extended through the cannula following the curvature of the dorsal rumen wall reaching into the gas phase of the rumen. The modified cannula lids were replaced $1 \mathrm{~h}$ before the first sampling of rumen gases, on d 21 of each experimental period. Using a syringe, two $60-\mathrm{mL}$ gas samples were collected into sealed N-purged 200-mL serum bottles. Sampling 
started $2 \mathrm{~h}$ after morning feeding and gas samples were collected hourly until $6 \mathrm{~h}$ postfeeding. Gas samples were analyzed for methane and $\mathrm{SF}_{6}$ by gas-liquid chromatography (Hewlett-Packard 5890 Series II GC connected to a Hewlett-Packard 5972 Series Mass Selective detector, Agilent Technologies Inc., Santa Clara, CA), equipped with PLOT capillary column GS-GasPro $60 \mathrm{~m} \times 0.320$ $\mu \mathrm{m}$ (SN US 3387916H Agilent Technologies, Inc.) under isothermal conditions at $25^{\circ} \mathrm{C}$ using ultrapure He as the carrier gas at a flow rate of $35 \mathrm{~cm} / \mathrm{s}$ linear velocity. Samples were analyzed by injecting $1 \mathrm{~mL}$ of sample gas into split/splitless port at $125^{\circ} \mathrm{C}$, programmed for a 5 -s split. The mass selective detector interface was maintained at $150^{\circ} \mathrm{C}$ and the mass detector acquired data over a mass/charge ratio from 10 to 250. Data on the relative abundance of methane and $\mathrm{SF}_{6}$ were extracted based on ion fragment with $\mathrm{m} / z$ ratios of 15 and 127, respectively, using Chemstation G1034 v. C.02.03 software (Agilent Technologies Inc.). External calibration was based on reference gas mix of methane, carbon dioxide, carbon monoxide, and $\mathrm{SF}_{6}$ (each $3 \pm$ $0.5 \%$ ) in N (Oxarc Inc., Spokane, WA). Production of methane was calculated as the release rate of $\mathrm{SF}_{6}$ times the ratio of the concentration of methane to $\mathrm{SF}_{6}$ in the ruminal headspace (Johnson et al., 1994).

The effect of treatment on ruminal methanogen populations was analyzed using denaturing gradient gel electrophoresis (DGGE). One-gram aliquots of whole ruminal contents composited by cow and period were used for extraction of total community DNA using the $\mathrm{RBB}+\mathrm{C}$ method ( $\mathrm{Yu}$ and Morrison, 2004). A methanogen-specific forward primer (344f-GC; Raskin et al., 1994) was used in PCR with the primer 519r (Lane, 1991) to amplify the V3 region of $16 \mathrm{~S}$ rRNA genes. The PCR amplifications were conducted in a total volume of $50 \mu \mathrm{L}$ containing $100 \mathrm{pmol}$ of each primer, $125 \mu \mathrm{M}$ of each dNTP, $2 \mathrm{~m} M$ magnesium chloride, $0.05 \%$ BSA, $1 \times$ PCR buffer, and 5.0 units of Platinum Taq DNA polymerase (Invitrogen, Carlsbad, CA). The thermoprofiles of PCR were the same as those reported previously (Karnati et al., 2009b). The PCR products were first verified on a 1\% agarose gel and then resolved on an $8 \%$ polyacrylamide gel (37.5:1) with a 60 to $80 \%$ denaturing gradient for $1,350 \mathrm{~V}$-h. After the run, gels were stained for $30 \mathrm{~min}$ in $0.5 \times$ Tris-borate-EDTA buffer containing SYBR Green nucleic acid stain (Molecular Probes, Eugene, OR), and banding patterns were documented using a FluorChem Imaging System (Alpha Innotech Corporation, San Leandro, CA). The images of the DGGE banding patterns were imported into the database in the BioNumerics software (BioSystematica, Devon, UK). Automated and manual alignment of the banding patterns to adjust for any possible migration differences was performed by pattern recognition us- ing external reference markers and internal reference bands. Cluster analysis was used to compare the banding patterns, and a dendrogram was constructed to illustrate pairwise similarities between all lanes in the gel (Karnati et al., 2009b).

Fecal samples (400 g per sampling) were collected from the rectum or the ground, when fresh, during the first $2 \mathrm{~d}$ of each sampling period at 0900, 1500, and $2100 \mathrm{~h}$ (d 15), and at 0300, 0600, 1200, 1800, and 0000 $\mathrm{h}(\mathrm{d} 16$ and 17$)$. Samples were dried at $65^{\circ} \mathrm{C}$ in a forcedair oven to constant weight, composited per animal and period, and ground through a 1-mm sieve. Samples were analyzed for ash/OM, N, NDF, starch, and AIA. Apparent total-tract digestibility was estimated using AIA as an intrinsic marker (Foley et al., 2006). At each sampling, an additional fecal sample (approximately $300 \mathrm{~g}$ ) was collected, composited (per cow and treatment), and frozen immediately $\left(-20^{\circ} \mathrm{C}\right)$ for the analysis of ammonia emissions from manure.

Total urine collection was performed during the last 4 d of each period. Urinary catheters (22 French, $75 \mathrm{~mL}$, C. R. Bard Inc., Covington, GA) were positioned in the cows $24 \mathrm{~h}$ before the initiation of the urine collection. Urine samples were acidified during collection to a $\mathrm{pH}$ $<3.0$ by addition of $2 M$ sulfuric acid. Aliquots were diluted 1:10 with distilled water, stored frozen at $-20^{\circ} \mathrm{C}$, and later analyzed for $\mathrm{N}$, allantoin (Chen, 1989), and uric acid (Uric acid kit 1051, Stanbio Laboratory, San Antonio, TX). Urinary excretion of allantoin and uric acid (PD) was used to estimate duodenal microbial N flow (MNF; Broderick and Merchen, 1992). At the beginning of each urine collection period, a nonacidified sample of urine (approximately $2 \mathrm{~L}$ ) was collected from each cow, frozen immediately $\left(-20^{\circ} \mathrm{C}\right)$, and subsequently used for the analysis of ammonia emissions from manure.

The ammonia emitting potential of manure resulting from the respective diet changes were measured in laboratory-scale postcollection simulated storages with appropriate instrumentation. This system, which consisted of a manure storage, an acid bottle to trap the emitted ammonia, a flow-meter to regulate sweep-air, and a vacuum pump to pull air through the system, was the same as that used in previous studies (Shi et al., 2001; Misselbrook et al., 2005; Ndegwa et al., 2009). Air to facilitate and carry emitted ammonia from the manure storage headspace was drawn using the vacuum pump at a flow rate of $1 \mathrm{~L} / \mathrm{min}$. The air carrying emitted ammonia was bubbled through a previously calibrated $0.2 \mathrm{M}$ sulfuric acid bottle to trap ammonia. Acid samples for the analysis of the trapped ammonia were collected daily during the first week and on alternate days during the second week. Samples were immediately analyzed for ammonia concentration using 
standard methods (APHA, 1998). The manure samples for these studies were reconstituted from the respective samples of feces and urine that had previously been collected separately and frozen. Frozen feces and urine were thawed at room temperature and mixed in the ratio of 1.7:1 (1,700 $\mathrm{g}$ of feces and 1,000 $\mathrm{g}$ of urine) on a weight basis to reconstitute the manure. The feces to urine excretion ratio in lactating dairy cows had been established in previous studies conducted in A. Hristov's laboratory (Vander Pol et al., 2007, 2008).

Milk yield was recorded daily and milk samples (p.m. and a.m. milkings) for composition analyses (fat, true protein, and MUN; Washington DHIA, Burlington, WA) were collected on $3 \mathrm{~d}$ during the last $10 \mathrm{~d}$ of each experimental period. Following the ${ }^{15} \mathrm{~N}$ dose, cows were milked at 0 (background), 5, 10, 15, 20, 25, 30, 35, 40, $45,50,55,60,65,70,75,80,85,90$, and $95 \mathrm{~h}$. At each milking, milk weights were recorded and milk samples were collected for the analysis of ${ }^{15} \mathrm{~N}$-enrichment of milk protein N (Hristov and Ropp, 2003).

Fatty acid composition was determined in untreated samples of milk collected during the last $24 \mathrm{~h}$ of each experimental period and composited according to yield. Milk samples for FA determinations were stored at $-20^{\circ} \mathrm{C}$ until submitted for analysis.

Lipid in $1 \mathrm{~mL}$ of milk was extracted in duplicate using diethylether/hexane (5:4, by vol) according to reference procedures (IDF 1C:1987; IDF 16C:1987; IDF , 1987). Extracts were combined and evaporated to dryness at $60^{\circ} \mathrm{C}$ under $\mathrm{O}_{2}$ free $\mathrm{N}_{2}$ for $1 \mathrm{~h}$. Samples were dissolved in hexane and methyl acetate and transesterified to fatty acid methyl esters (FAME) using freshly prepared methanolic sodium methoxide (Christie, 1982) with modifications (Shingfield et al., 2003). Methyl esters were quantified using a gas chromatograph (model 6890; Hewlett-Packard, Wilmington, DE) equipped with a flame-ionization detector and a $100-\mathrm{m}$ fused silica capillary column (i.d., $0.25 \mathrm{~mm}$ ) coated with $0.2 \mu \mathrm{m}$ film of cyanopropyl polysiloxane (CP-SIL 88, Chrompack 7489, Middelburg, the Netherlands). Injector and detector temperatures were maintained at $255^{\circ} \mathrm{C}$. Total FAME profile in a $2-\mu \mathrm{L}$ sample volume at a split ratio of 1:50 was determined using a temperature gradient program with $\mathrm{H}_{2}$ as the carrier gas operated at constant pressure at a flow rate of $0.5 \mathrm{~mL} / \mathrm{min}$ (Shingfield et al., 2003). Isomers of $18: 1$ and 18:2 were further resolved in a separate analysis under isothermal conditions at $170^{\circ} \mathrm{C}$ (Shingfield et al., 2003). Peaks were identified based on retention time comparisons with authentic standards (GLC \#463 and GLC \#606, Nu-Chek Prep, Elysian, MN). Methyl esters not contained in commercially available standards were formally identified by GC-MS analysis of 4,4-dimethyloxazoline fatty acid derivatives prepared from FAME by incubation overnight with 2-amino, 2-methyl-1-propanol under a $\mathrm{N}$ atmosphere at $150^{\circ} \mathrm{C}$ (Shingfield et al., 2006). Impact ionization spectra of 4,4-dimethyloxazoline derivatives were obtained using an identical gas chromatograph equipped with a selective quadrupole mass detector (model 5973N, Agilent Technologies Inc., Wilmington, $\mathrm{DE})$, under an ionization voltage of $70 \mathrm{eV}$. Chromatography was achieved under a temperature gradient used for the analysis of FAME and He as the carrier gas (Shingfield et al., 2006). Double-bond geometry was determined based on atomic mass unit distances, with an interval of 12 atomic mass units between the most intense peaks of clusters of ions containing $\mathrm{n}$ and n-1 carbon atoms being interpreted as cleavage of the double bond between carbon $n$ and $n+1$ in the fatty acid moiety.

Following gas-liquid chromatography analysis, samples of milk fat FAME were evaporated under oxygen-free $\mathrm{N}$, dissolved in heptanes, and the distribution of CLA isomers was determined by HPLC using 4 silver-impregnated silica columns (ChromSpher 5 lipids, $250 \times 4.6 \mathrm{~mm} ; 5 \mu \mathrm{m}$ particle size, Varian Ltd., Walton-on-Thames, UK) coupled in series, $0.1 \%$ (vol/ vol) acetonitrile in heptane as the mobile phase and monitoring column effluent at 233 and $210 \mathrm{~nm}$ (Shingfield et al., 2003). Isomers were identified using an authentic CLA methyl ester standard (O-5632, SigmaAldrich, YA-Kemia Limited, Helsinki, Finland) and chemically synthesized trans-9, cis-11-CLA (Shingfield et al., 2005). Identification was verified by cross-referencing with the elution order reported in the literature (Delmonte et al., 2005).

Milk FA composition was expressed as a weight percentage of total fatty acids using theoretical relative response factors (Craske and Bannon, 1988; Ulberth et al., 1999), and milk fat FA content was calculated assuming that milk fat was secreted as triacylglycerides and that singlet hydrogen and oxygen atoms are removed from the glycerol moiety during FA esterification (Glasser et al., 2007). Concentrations of specific CLA isomers were calculated based on proportionate peak area responses determined by HPLC and the sum of trans-7, cis-9 CLA, trans-8, cis-10 CLA, and cis-9, trans-11 CLA weight percentage determined by GC.

On d 20 of each experimental period, blood samples were collected from the tail vein/artery immediately before and $6 \mathrm{~h}$ after morning feeding. Plasma was obtained by centrifugation at $1,500 \times g$ for $40 \mathrm{~min}$, frozen at $-40^{\circ} \mathrm{C}$, and later analyzed for urea $\mathrm{N}$ (kit 0580, Stanbio Laboratory) concentration. Body weight of the cows was recorded at the beginning of the experiment and at the end of each experimental period. 


\section{Calculations}

Pool size of ruminal ammonia $\mathrm{N}$, areas under the ${ }^{15} \mathrm{~N}$-enrichment atom percent excess curves (AUC) for ruminal ammonia (Figure 4), bacteria and WRC (Figure 5), and milk protein (Figure 7), and the proportions of milk protein $\mathrm{N}$ originating from ruminal bacterial and ammonia $\mathrm{N}$ and the proportion of bacterial $\mathrm{N}$ originating from ruminal ammonia $\mathrm{N}$ were calculated as described elsewhere (Hristov et al., 2005). The average adjusted $\mathrm{r}^{2}( \pm \mathrm{SE})$ for the ruminal ammonia, bacterial, and WRC N models were $0.98 \pm 0.006,0.97 \pm 0.009$, and $0.93 \pm 0.016$, respectively. The average proportion of the variance explained by the milk protein model (regression sum of squares $\div$ uncorrected total sum of squares) was $0.96 \pm 0.007$. Total flux, irreversible loss, recycling rate, and the efficiency of utilization of ruminal ammonia $\mathrm{N}$ for microbial protein synthesis were calculated as described in Hristov et al. (2005).

The cumulative amount of ${ }^{15} \mathrm{~N}$ secreted in milk protein (as percentage of ${ }^{15} \mathrm{~N}$ dosed) was fitted to a single rectangular 2-parameter hyperbola model and the estimated maximum secretion and overall secretion lines were compared among treatments using the dummy variable regression technique (PROC NLIN of SAS; Hristov et al., 2005). The average proportion of the variance explained by the model (regression sum of squares $\div$ uncorrected total sum of squares) was 0.91 \pm 0.010 .

The amount of microbial N (MN) in WRC was estimated according to 2 approaches. In the first approach, WRC ${ }^{15} \mathrm{~N}$-enrichment curves were fitted to a 3-parameter exponential decay model to estimate AUC (Hristov et al., 2005). The proportion of $\mathrm{MN}$ in $\mathrm{WRC}$ was derived as $\mathrm{AUC}_{\mathrm{WRC}} \div \mathrm{AUC}_{\text {Bacterial } \mathrm{N}}$, and the amount of $\mathrm{MN}$ in WRC was calculated as follows: ruminal DM (from rumen evacuation) $\times$ concentration of NAN in WRC $\times$ proportion of MN in WRC. The second approach utilized what appeared to be a steady state period of ${ }^{15} \mathrm{~N}$ exchange between the WRC and bacterial N pools. During this period (sampling time points 1 through 8 $\mathrm{h}$ post- ${ }^{15} \mathrm{~N}$ dose, points in rectangle in Figure 6), the ratio of $\mathrm{WRC}^{-15} \mathrm{~N} \div$ bacterial ${ }^{15} \mathrm{~N}$ was relatively stable (mean of $0.46 \pm 0.009$; effect of time of sampling across treatments, $P=0.14$ ).

Urinary PD excretion was used to estimate duodenal MN flow assuming that 1) absorption of microbial purine bases $(\mathrm{MPB} ; \mathrm{mmol} / \mathrm{d})=\left(\mathrm{PD}-0.385 \times \mathrm{BW}^{0.75}\right)$ $\div 0.85$, where $\mathrm{PD}$ is the urinary $\mathrm{PD}$ excretion (allantoin and uric acid; mmol/d), $0.385 \mathrm{mmol} / \mathrm{kg} \mathrm{BW}^{0.75}$ is a correction for endogenous $\mathrm{PD}$, and 0.85 is a recovery coefficient (Verbic et al., 1990); and 2) Duodenal MN flow $(\mathrm{g} \mathrm{N} / \mathrm{d})=($ absorbed MPB $\times 70) \div(0.83 \times 0.134$ $\times 1,000)$, where 70 is the $\mathrm{N}$ content of purines $(\mathrm{mg} \mathrm{N} /$ mmol; Chen et al., 1992) and 0.134 is the ratio of purine $\mathrm{N}$ to total $\mathrm{N}$ in rumen microorganisms assumed based on the data of Valadares et al. (1999) and a digestibility coefficient of 0.83 for microbial purines (Chen et al., 1992).

\section{Statistical Analysis}

Data were analyzed using PROC MIXED of SAS (SAS Inst., Inc., Cary, NC). Intake, digestibility, most of the rumen fermentation data, urinary excretion measurements, milk yield and composition, some of the ${ }^{15} \mathrm{~N}$-enrichment data, and end-point (d 15) cumulative ammonia emission from manure data were analyzed by ANOVA Latin square. Milk composition data collected during each experimental period were averaged per cow and the average values were used in the statistical analysis and to calculate FCM, energy-corrected milk, and milk fat and protein yields. Data were analyzed according to the following model:

$$
\mathrm{Y}_{\mathrm{ijkl}}=\mu+\mathrm{G}_{\mathrm{i}}+\mathrm{C}(\mathrm{G})_{\mathrm{ij}}+\mathrm{P}_{\mathrm{k}}+\tau_{\mathrm{l}}+\mathrm{e}_{\mathrm{ijkl}},
$$

where $\mu$ is the overall mean, $G_{i}$ is the group, $C(G)_{i j}$ is the cow within group, $P_{k}$ is the kth period, $\tau_{1}$ is the lth treatment, with the error term $\mathrm{e}_{\mathrm{ijk}}$ assumed to be normally distributed with mean $=0$ and constant variance. Group and cow within group were random effects whereas all other factors were fixed.

Ruminal pH, ammonia concentration, and methane production data and ${ }^{15} \mathrm{~N}$ enrichment of ammonia $\mathrm{N}$, $\mathrm{BN}$, WRC, and milk protein $\mathrm{N}$ (MPN) data were analyzed as Latin square repeated measures assuming an autoregressive [1] covariance structure fitted based on Akaike information and Schwarz-Bayesian model-fit criteria according to the following model:

$$
\begin{aligned}
Y_{\mathrm{ijklm}}=\mu+ & \mathrm{G}_{\mathrm{i}}+\mathrm{C}(\mathrm{G})_{\mathrm{ij}}+\mathrm{P}_{\mathrm{k}}+\tau_{1}+\mathrm{D}_{\mathrm{m}} \\
& +\tau \mathrm{D}_{\mathrm{lm}}+\mathrm{e}_{\mathrm{ijklm}},
\end{aligned}
$$

where $\mu$ is the overall mean, $G_{i}$ is the group, $C(G)_{i j}$ is the cow within group, $\mathrm{P}_{\mathrm{k}}$ is the kth period, $\tau_{1}$ is the lth treatment, $D_{m}$ is the time effect, $\tau D_{l m}$ is the treatment $\times$ time interaction with the error term $\mathrm{e}_{\mathrm{ijklm}}$ assumed to be normally distributed with mean $=0$ and constant variance. Group and cow within group were random effects whereas all others were fixed.

Cumulative ammonia emission from manure data were fitted to a linear model $\left(\mathrm{r}^{2}=0.99\right)$ and analyzed by linear regression (cumulative ammonia emission, mg of $\mathrm{N}=$ intercept + slope $\times$ incubation day; PROC GLM of SAS). 
Statistical differences were declared at $P \leq 0.05$. Differences between treatments at $P \leq 0.10$ were considered as a trend toward significance.

\section{RESULTS}

Ruminal $\mathrm{pH}$ was higher $(P=0.04)$ for $\mathrm{CO}$ versus the control (SA) and LA (Table 2). Treatment $\times$ sampling time interactions were not significant $(P=0.35)$ for ruminal $\mathrm{pH}$. Concentration of ammonia in ruminal fluid was reduced $(P=0.03$; treatment $\times$ time interaction, $P=0.87)$ and the ammonia $\mathrm{N}$ pool was numerically smaller $(P=0.11)$ for CO and LA compared with the control. In spite of the large variability, ammonia concentration was lower for LA and $\mathrm{CO}$ compared with the control during the initial hours after feeding and treatment application (Figure 1). Concentration of TFAA was numerically lower $(P=0.11)$ in LA and CO compared with the control. Compared with the control, $\mathrm{CO}$ tended to reduce $(P=0.09)$ total VFA concentration in ruminal fluid. Butyrate concentration was decreased $(P=0.002)$ by both LA and $\mathrm{CO}$ and propionate concentration was increased $(P<0.001)$ by LA compared with the control. Treatments had no effect $(P=0.19$ to 0.99) on rumen acetate, branched-chain VFA, and valerate concentrations. Because of the increased concentration of propionate, LA resulted in a lower $(P=0.03)$ acetate:propionate ratio compared with the control and CO. Total protozoal counts were substantially reduced $(P=0.003)$ by both LA and CO compared with the control. A similar effect was observed for Entodinium and Dasytricha spp. ( $P=0.004$ and 0.04 , respectively). Treatments had no effect $(P=0.12$ to 0.79$)$ on the other genera of protozoa. Entodinium spp. represented 91 to $96 \%$ of the rumen protozoal population in this experiment. The refaunation procedure implemented during the transition between experimental periods was effective in restoring the protozoal counts in the rumen of LA and CO-treated cows. The average $(\mathrm{n}=6)$ total protozoal counts on $\mathrm{d} 1$ of periods 2 and 3 were $68.7 \pm$ 10.2 and $62.3 \pm 7.4 \times 10^{4} / \mathrm{mL}$ (respectively), which was comparable to the counts on $\mathrm{d} 1$ of the experiment (i.e., d 1 of period 1), $74.5 \pm 8.4 \times 10^{4} / \mathrm{mL}$.

Carboxymethylcellulase activity of ruminal fluid was decreased by LA and xylanase activity tended $(P=$ $0.08)$ to be decreased by LA and CO compared with the control. Amylase activity was not different $(P=$ $0.66)$ among treatments. Methane production rate in the rumen was decreased $(P=0.05$; treatment $\times$ time interaction, $P=0.18$ ) by CO compared with the control and LA. Despite large variation in the data, methane production rate was the lowest for $\mathrm{CO}$ throughout the sampling period (Figure 2). Methanogen-specific DGGE was performed on composited rumen samples collected at different time points during the feeding cycle. The banding patterns were then merged using the BioNumerics software for cluster analysis, which provides a method of objectively determining groups of similar patterns based on the normalized gels using external (molecular weight markers) and internal reference bands. About 9 to 10 bands were amplified from all the samples (Figure 3). Despite changes in relative abundances of some of the bands in the gel, the samples tended to cluster mostly by experimental period and treatment did not seem to have any specific effect on the DGGE banding patterns. The fractional outflow rate of ruminal fluid and the size of the ruminal NAN and microbial NAN pools were similar $(P=0.63$ to 0.89 ) among treatments. Urinary allantoin, uric acid, and total PD excretion were also similar $(P=0.16$ to 0.32 ) among treatments. Urinary excretion of allantoin, and consequently total $\mathrm{PD}$, were numerically lower (treatment means comparison, $P=0.06$ ) for $\mathrm{CO}$ compared with the control. Similarly, the estimated MNF was numerically lower (treatment means comparison, $P=0.06)$ for $\mathrm{CO}$ compared with the control. Concentration of plasma urea $\mathrm{N}$ was comparable $(P=0.41)$ across treatments. Treatments had no effect on intake $(P=0.19$ to 0.34$)$ or total-tract apparent digestibility $(P=0.13$ to 0.38$)$ of DM, OM, N, NDF, and starch (Table 3).

Urinary $\mathrm{N}$ excretion tended to be lower $(P=0.09)$ for CO compared with the control and LA (Table 4). As a proportion of intake, urinary $\mathrm{N}$ losses were higher $(P=0.02)$ or tended to be higher $(P=0.07)$ for LA compared with $\mathrm{CO}$ and the control, respectively. There were no differences ( $P=0.19$ to 0.70$)$ because of treatment in fecal absolute and relative $\mathrm{N}$ excretion or total urinary and fecal $\mathrm{N}$ losses.

Milk production of the cows (including FCM and ECM), milk efficiency, milk fat, protein, and lactose content and yields, and MUN were not affected $(P=$ 0.23 to 0.92 ) by treatment (Table 5 ). Treatments also had no effect $(P=0.79)$ on cow BW.

Mean ${ }^{15} \mathrm{~N}$ enrichment of ruminal ammonia, bacterial and WRC NAN, and milk protein $\mathrm{N}$ were similar $(P$ $=0.58$ to 0.81 ) across treatments (Table 6). Enrichment of ${ }^{15} \mathrm{~N}$ in ruminal ammonia $\mathrm{N}$ declined rapidly $(P<0.001)$ after ${ }^{15} \mathrm{~N}$ administration and within $4 \mathrm{~h}$ approached natural abundance (Figure 4). Similarly, ${ }^{15} \mathrm{~N}$ enrichment of ruminal bacterial and WRC NAN decreased $(P<0.001)$ exponentially following the pulse dosing of ${ }^{15} \mathrm{~N}$ at time $0 \mathrm{~h}$ (Figure 5). Treatment $\times$ time interactions were not significant $(P=0.56$ to 0.99$)$ for rumen $\mathrm{N}$ pools, with the exception that ${ }^{15} \mathrm{~N}$ enrichment of WRC NAN at $0 \mathrm{~h}$ was higher for LA compared with the control or $\mathrm{CO}(P<0.001$ and $P=0.002$, respectively). The ratio of ${ }^{15} \mathrm{~N}$ enrichment of WRC NAN: ${ }^{15} \mathrm{~N}$ 
Table 2. Effect of lauric acid (LA) and coconut oil (CO) on rumen fermentation, urinary excretion of purine derivatives, and blood urea $\mathrm{N}$ in dairy cows ${ }^{1}$

\begin{tabular}{|c|c|c|c|c|c|}
\hline Item & Control & LA & $\mathrm{CO}$ & SEM & $P$-value \\
\hline \multicolumn{6}{|l|}{ Rumen } \\
\hline $\mathrm{pH}$ & $6.21^{\mathrm{b}}$ & $6.22^{\mathrm{b}}$ & $6.37^{\mathrm{a}}$ & 0.041 & $0.04^{2}$ \\
\hline $\mathrm{NH}_{3}, \mathrm{~m} M$ & $10.2^{\mathrm{a}}$ & $7.9^{\mathrm{b}}$ & $7.9^{\mathrm{b}}$ & 1.11 & $0.03^{3}$ \\
\hline Rumen $\mathrm{NH}_{3} \mathrm{~N}$ pool, ${ }^{4} \mathrm{~g}$ & 8.3 & 5.7 & 5.4 & 1.20 & 0.11 \\
\hline $\mathrm{TFAA}^{5}{ }^{5} \mathrm{~m} M$ & 1.8 & 1.5 & 1.5 & 0.10 & 0.11 \\
\hline Total VFA, $\mathrm{m} M$ & 94.2 & 91.5 & 84.9 & 3.22 & $0.09^{6}$ \\
\hline Acetate & 56.6 & 53.3 & 51.7 & 2.26 & 0.31 \\
\hline Propionate & $20.7^{\mathrm{b}}$ & $23.8^{\mathrm{a}}$ & $19.5^{\mathrm{b}}$ & 1.83 & $<0.001^{7}$ \\
\hline Isobutyrate & 1.11 & 1.01 & 0.93 & 0.096 & 0.19 \\
\hline Butyrate & $11.8^{\mathrm{a}}$ & $9.4^{\mathrm{b}}$ & $8.9^{\mathrm{b}}$ & 0.48 & 0.002 \\
\hline Isovalerate & 1.56 & 1.57 & 1.58 & 0.136 & 0.99 \\
\hline Valerate & 2.48 & 2.36 & 2.32 & 0.145 & 0.62 \\
\hline Acetate:propionate & $2.96^{\mathrm{a}}$ & $2.27^{\mathrm{b}}$ & $2.76^{\mathrm{a}}$ & 0.284 & 0.03 \\
\hline Total protozoa, $\times 10^{4} / \mathrm{mL}$ & $138.2^{\mathrm{a}}$ & $27.2^{\mathrm{b}}$ & $22.9^{\mathrm{b}}$ & 17.75 & $0.003^{8}$ \\
\hline Entodinium spp. & 132.6 & 25.8 & 20.9 & 16.83 & 0.004 \\
\hline Isotricha spp. & 1.2 & 0.5 & 0.3 & 0.36 & 0.79 \\
\hline Dasytricha spp. & $1.5^{\mathrm{a}}$ & $0.4^{\mathrm{b}}$ & $0.4^{\mathrm{b}}$ & 0.18 & 0.04 \\
\hline Epidinium spp. & 0.3 & $\mathrm{ND}^{9}$ & ND & 0.15 & 0.57 \\
\hline Ophryoscolex spp. & 1.1 & ND & 0.5 & 0.56 & 0.12 \\
\hline Diplodinium spp. & 1.6 & 0.5 & 0.7 & 0.53 & 0.51 \\
\hline \multicolumn{6}{|l|}{ PSD activities ${ }^{10}$} \\
\hline CMCase & $149^{\mathrm{a}}$ & $94^{\mathrm{b}}$ & $107^{\mathrm{a}}$ & 11.4 & $0.04^{11}$ \\
\hline Xylanase & 216 & 153 & 150 & 16.9 & $0.08^{12}$ \\
\hline Amylase & 133 & 149 & 123 & 23.2 & 0.66 \\
\hline Methane production, $\mathrm{g} / \mathrm{h}$ & $6.5^{\mathrm{a}}$ & $7.1^{\mathrm{a}}$ & $2.5^{\mathrm{b}}$ & 1.47 & $0.05^{13}$ \\
\hline Liquid phase FOR, ${ }^{14} \% / \mathrm{h}$ & 11.9 & 10.8 & 7.2 & 2.58 & 0.40 \\
\hline WRC NAN,${ }^{15} \mathrm{~kg}$ & 0.264 & 0.246 & 0.255 & 0.0308 & 0.89 \\
\hline $\mathrm{MN}$ in $\mathrm{WRC},{ }^{16} \mathrm{~kg}$ & 0.148 & 0.127 & 0.133 & 0.0188 & 0.63 \\
\hline $\mathrm{MN}$ in $\mathrm{WRC},{ }^{17} \mathrm{~kg}$ & 0.130 & 0.110 & 0.115 & 0.0162 & 0.69 \\
\hline \multicolumn{6}{|l|}{ Urinary $\mathrm{PD},{ }^{18} \mathrm{mmol} / \mathrm{d}$} \\
\hline Allantoin & 441 & 390 & 332 & 43.2 & $0.16^{19}$ \\
\hline Uric acid & 69 & 61 & 53 & 10.2 & 0.32 \\
\hline Total PD & 510 & 451 & 384 & 50.4 & $0.16^{19}$ \\
\hline $\mathrm{MN},{ }^{20} \mathrm{~g} / \mathrm{d}$ & 339 & 296 & 247 & 36.9 & $0.16^{21}$ \\
\hline $\mathrm{PUN}^{22} \mathrm{mg} / 100 \mathrm{~mL}$ & 21.2 & 18.0 & 18.3 & 1.97 & 0.41 \\
\hline
\end{tabular}

${ }^{\mathrm{a}, \mathrm{b}}$ Within a row, means without a common superscript letter differ $(P<0.05)$.

${ }^{1}$ Data are reported as least squares means; $\mathrm{n}=180$, rumen $\mathrm{pH}$ and ammonia data; $\mathrm{n}=90$, rumen methane; and $\mathrm{n}=18$, all other variables.

${ }^{2}$ Treatment $\times$ time interaction, $P=0.35$.

${ }^{3}$ Treatment $\times$ time interaction, $P=0.87$.

${ }^{4}$ Rumen ammonia $\mathrm{N}$ pool size $(\mathrm{g})$ estimated from ruminal evacuation data and ammonia concentration in ruminal fluid.

${ }^{5}$ Total free amino acids; control vs. LA, $P=0.06$; control vs. CO, $P=0.09$.

${ }^{6}$ Control vs. CO, $P=0.04$.

${ }^{7}$ Control vs. $\mathrm{CO}, P=0.10$

${ }^{8}$ Actual protozoal counts were $\log _{10}$ transformed for the statistical analysis.

${ }^{9}$ Low counts - below $0.02 \times 10^{4} / \mathrm{mL}$.

${ }^{10} \mathrm{PSD}=$ polysaccharide-degrading activities. Expressed as nanomoles of reducing sugars as glucose released/ $\mathrm{mL}$ of ruminal fluid per min; CMCase $=$ carboxymethylcellulase .

${ }^{11}$ Control vs. $\mathrm{CO}, P=0.053$

${ }^{12}$ Control vs. CO, $P=0.046$; control vs. LA, $P=0.053$.

${ }^{13}$ Treatment $\times$ time interaction, $P=0.18$.

${ }^{14} \mathrm{FOR}=$ fractional outflow rate.

${ }^{15}$ Nonammonia $\mathrm{N}$ in whole ruminal contents (WRC) before feeding $(0 \mathrm{~h})$ determined by rumen evacuation.

${ }^{16}$ Microbial NAN (MN) in WRC before feeding $(0 \mathrm{~h})$ estimated based on areas under the ${ }^{15} \mathrm{~N}$-enrichment curves (see Materials and Methods and Table 6).

${ }^{17}$ Microbial NAN in WRC before feeding $(0 \mathrm{~h})$ estimated based on steady state ${ }^{15} \mathrm{~N}$-enrichment (time points 1 through $8 \mathrm{~h}$ ) of WRC and bacterial N (see Materials and Methods and Figure 6).

${ }^{18}$ Excretion of urinary purine derivatives (PD).

${ }^{19}$ Control vs. CO, $P=0.06$.

${ }^{20}$ Estimated microbial N outflow from the rumen (based on urinary PD excretion).

${ }^{21}$ Control vs. CO, $P=0.06$.

${ }^{22} \mathrm{PUN}=$ blood plasma urea $\mathrm{N}$. 


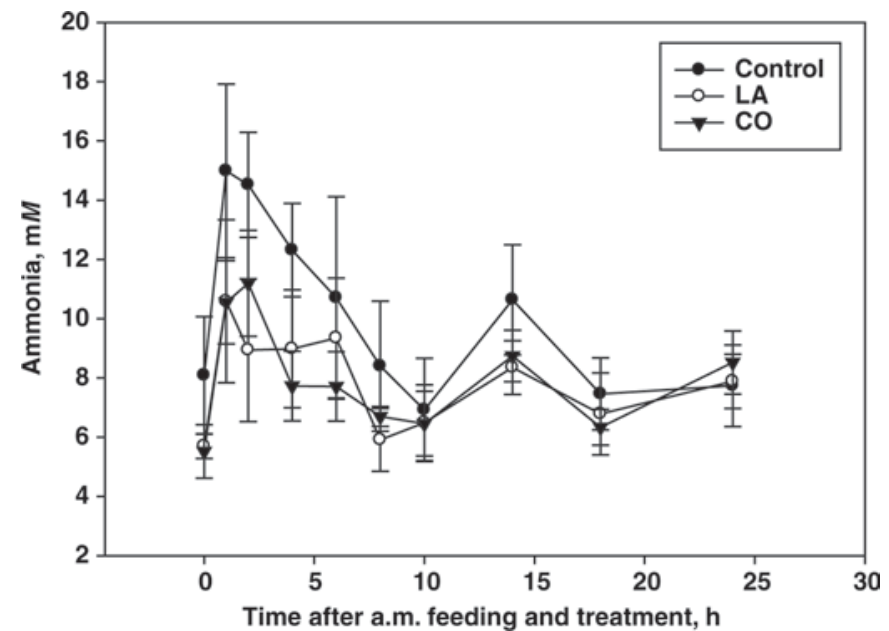

Figure 1. Effect of lauric acid (LA) and coconut oil (CO) on ruminal ammonia concentration in dairy cows (means $\pm \mathrm{SE} ; \mathrm{n}=180$ ). Overall treatment effect, $P=0.03$; treatment $\times$ time interaction, $P$ $=0.87$.

enrichment of bacterial NAN increased $(P<0.001)$ over time, reaching 0.80 to $0.8524 \mathrm{~h}$ after ${ }^{15} \mathrm{~N}$ dosing (Figure 6). However, from 1 to $8 \mathrm{~h}$ posttreatment (points in the rectangle in Figure 6), ${ }^{15} \mathrm{~N}$ enrichment of bacterial and WRC NAN appeared to be in equilibrium (effect of time, $P=0.14$ ). Thus, the average ratio of WRC $\mathrm{NA}^{15} \mathrm{~N}$ :bacterial $\mathrm{NA}^{15} \mathrm{~N}$ for these time points was used to estimate the amount of MN in WRC (Table 2 ). Areas under the ${ }^{15} \mathrm{~N}$ enrichment curves were similar

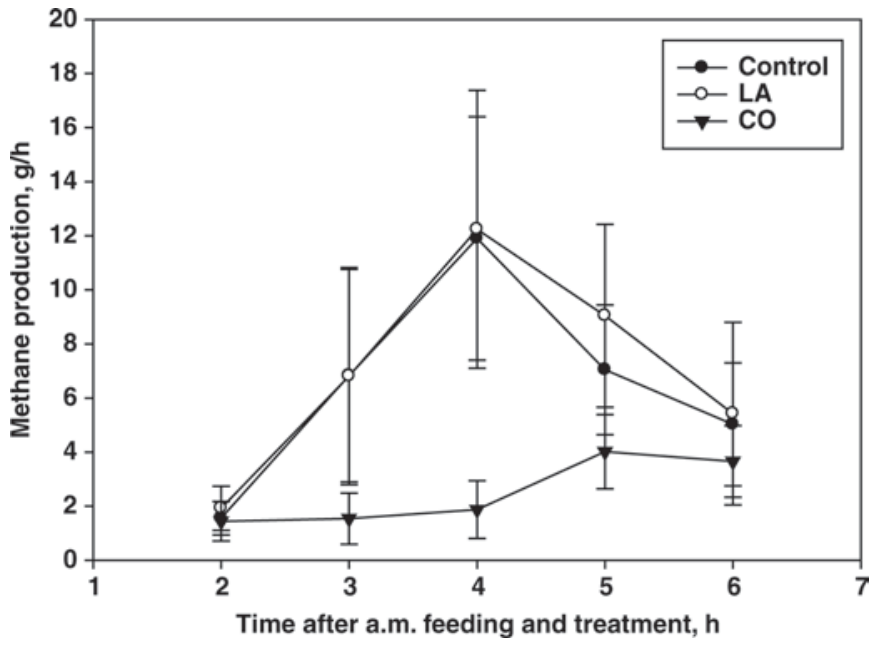

Figure 2. Effect of lauric acid (LA) and coconut oil (CO) on ruminal methane production rate in dairy cows (means $\pm \mathrm{SE} ; \mathrm{n}=90$ ). Overall treatment effect, $P=0.05$; treatment $\times$ time interaction, $P$ $=0.18$.

for ammonia $\mathrm{N}$ and MPN $(P=0.33$ and 0.91 , respectively) but were greater for LA and CO compared with the control for $\mathrm{BN}$ and WRC $(P=0.003$ and 0.01 , respectively). Secretion of ${ }^{15} \mathrm{~N}$ in milk protein followed a typical temporal pattern (Figure 7) consistent with previous studies (Hristov et al., 2005). Even though the cumulative amount of ammonia ${ }^{15} \mathrm{~N}$ secreted in milk over a 95 -h period was the highest $(P<0.001$ to 0.04 ) for the control followed by LA and CO (Figure

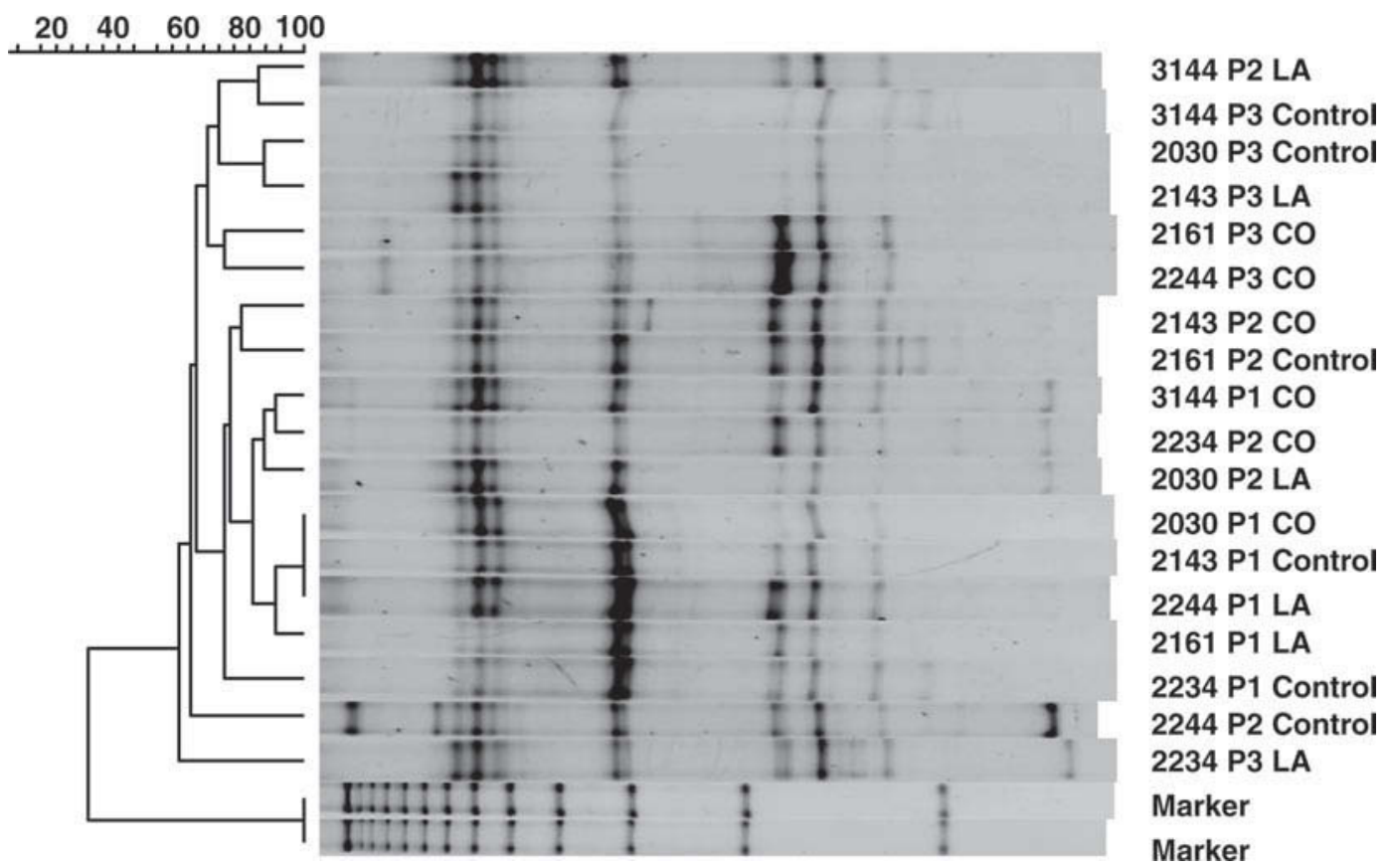

Figure 3. Denaturing gradient gel electrophoresis profiles of methanogens produced from community DNA samples from whole ruminal contents from cows fed control, lauric acid (LA), or coconut oil (CO) supplemented diets. The lanes are labeled with the cow number, period (P) number, and treatment. The calculated similarity coefficients determined using Bionumerics software are shown on the top left-hand side. 
Table 3. Effect of lauric acid (LA) and coconut oil (CO) on intake and total tract apparent digestibility of nutrients in dairy cows ${ }^{1}$

\begin{tabular}{lccccc}
\hline Item & Control & LA & CO & SEM & $P$-value \\
\hline Intake, $\mathrm{kg} / \mathrm{d}$ & & & & & \\
DM & 26.5 & 24.0 & 24.5 & 2.17 & 0.20 \\
OM & 23.7 & 21.5 & 21.9 & 1.94 & 0.21 \\
N & 0.676 & 0.612 & 0.626 & 0.0554 & 0.20 \\
NDF & 8.6 & 7.7 & 7.9 & 0.70 & 0.19 \\
Starch & 6.5 & 6.0 & 5.9 & 0.53 & 0.34 \\
Apparent digestibility, \% & & & & & \\
DM & 68.0 & 71.9 & 66.3 & 2.19 & 0.22 \\
OM & 69.5 & 73.5 & 68.2 & 2.25 & 0.26 \\
N & 66.3 & 70.5 & 64.2 & 2.29 & 0.19 \\
NDF & 60.8 & 64.5 & 56.7 & 2.70 & 0.13 \\
Starch & 89.3 & 89.7 & 87.4 & 1.34 & 0.38 \\
\hline
\end{tabular}

${ }^{1}$ Data are reported as least squares means; $\mathrm{n}=18$.

8), treatments had no effect ( $P=0.54$ to 0.96$)$ on the theoretical maximum of ammonia ${ }^{15} \mathrm{~N}$ secretion in milk. The proportion of bacterial $\mathrm{N}$ in WRC-NAN, bacterial $\mathrm{N}$ originating from ammonia $\mathrm{N}$, and the proportion of MPN originating from ammonia $\mathrm{N}$, estimated based on the ${ }^{15} \mathrm{~N}$-AUC, were not different $(P=0.11$ to 0.44$)$ among treatments. The proportion of MPN originating from bacterial $\mathrm{N}$ was lower $(P=0.05)$ for $\mathrm{LA}$ and $\mathrm{CO}$ compared with the control. Irreversible loss of ruminal ammonia $\mathrm{N}$, absolute or relative to $\mathrm{N}$ intake, was not different $(P=0.38$ and 0.46 , respectively) among treatments. Ammonia $\mathrm{N}$ flux was reduced $(P=0.006)$ by both LA and $\mathrm{CO}$ compared with the control. As proportion of $\mathrm{N}$ intake, ammonia $\mathrm{N}$ flux was lower $(P$ $=0.02)$ for $\mathrm{CO}$ and tended to be lower $(P=0.07)$ for LA compared with the control. Treatment had no effect on ammonia $\mathrm{N}$ recycling or the efficiency of utilization of ammonia $\mathrm{N}$ for microbial protein synthesis in the rumen $(P=0.87$ and 0.43 , respectively).

Ruminal administration of LA or CO altered milk FA composition relative to the control treatment. Compared with the control, LA increased $(P<0.001)$ milk fat 12:0, cis-9 12:1, and trans-9 12:1 content and decreased $(P<0.001$ to 0.02$)$ 4:0, 6:0, 8:0, 10:0, cis-9 10:1, 16:0, trans $16: 1,18: 0$, cis 18:1, total 18:2, 18:3 n-3, and total PUFA concentrations (Table 7). Lauric acid also altered $(P<0.001$ to 0.006$)$ the concentrations of several minor FA including 13:0 iso, cis-11 16:1, trans-12 16:1, 17:0, and 17:0 anteiso, but although significant, the magnitude of these changes relative to the control was relatively minor. Administration of $\mathrm{CO}$ enhanced $(P<0.001$ to 0.009$)$ milk fat $12: 0$, cis-9 $12: 1$, trans-9 12:1, 14:0, cis-9 14:1, and trans $16: 1$ and tended $(P=$ $0.09)$ to increase total trans fatty acids concentrations, but decreased $(P<0.001$ to 0.008$) 6: 0,8: 0,10: 0$, cis-9 10:1, 16:0, 18:0, cis 18:1, total 18:2, 18:3 n-3, and total PUFA content compared with the control treatment. Milk on the CO treatment contained higher amounts $(P<0.001$ to 0.05$)$ of $14: 0$, cis-9 $14: 1$, cis-11 16:1, and trans-9 16:1, and lower $(P<0.001$ to 0.03$)$ proportions of 15:0 anteiso, 17:0, 17:0 iso, 17:0 anteiso, cis 18:1, 20:0, cis-9 20:1, 22:0, 22:5 n-6, 23:0, 24:0, and 26:0 relative to LA.

Compared with the control, LA enhanced $(P<0.001$ to 0.03) cis-13 18:1, cis-15 18:1, cis-16 18:1, trans-12 18:1, and trans-13-14 18:1 concentrations and decreased $(P$

Table 4. Effect of lauric acid (LA) and coconut oil (CO) on urinary and fecal $\mathrm{N}$ losses in dairy cows ${ }^{1}$

\begin{tabular}{lccccc}
\hline Item & Control & LA & CO & SEM & $P$-value \\
\hline Urinary N & & & & & \\
kg/d & 0.251 & 0.252 & 0.203 & 0.0183 & $0.09^{2}$ \\
As \% of N intake & $37.0^{\mathrm{ab}}$ & $42.0^{\mathrm{a}}$ & $33.1^{\mathrm{b}}$ & 2.32 & $0.02^{3}$ \\
Fecal N & 0.227 & 0.180 & 0.234 & 0.0317 & 0.26 \\
kg/d & 33.7 & 29.5 & 35.8 & 2.29 & 0.19 \\
As \% of N intake & & & & \\
Total urinary and fecal N losses & 0.478 & 0.432 & 0.438 & 0.0401 & 0.47 \\
kg/d & 70.7 & 71.5 & 68.8 & 2.08 & 0.70 \\
As \% of N intake &
\end{tabular}

\footnotetext{
${ }^{\mathrm{a}, \mathrm{b}}$ Within a row, means without a common superscript letter differ $(P<0.05)$.

${ }^{1}$ Data are reported as least squares means; $\mathrm{n}=18$.

${ }^{2}$ Control vs. CO and CO vs. LA, $P=0.06$.

${ }^{3}$ Control vs. LA, $P=0.07$; control vs. CO, $P=0.14$.
} 
Table 5. Effect of lauric acid (LA) and coconut oil (CO) on milk yield and composition in dairy cows ${ }^{1}$

\begin{tabular}{lccccc}
\hline Item & Control & LA & CO & SEM & $P$-value \\
\hline Milk yield, kg/d & 30.4 & 29.1 & 29.0 & 2.54 & 0.75 \\
Milk/DMI & 1.09 & 1.11 & 1.11 & 0.093 & 0.92 \\
Milk fat, \% & 3.60 & 3.39 & 3.46 & 0.159 & 0.50 \\
Yield, kg/d & 1.07 & 0.98 & 0.99 & 0.080 & 0.29 \\
$4 \%$ FCM, kg/d & 28.3 & 26.4 & 26.5 & 2.13 & 0.43 \\
Milk true protein, \% & 3.11 & 3.05 & 3.04 & 0.090 & 0.38 \\
Yield, kg/d & 0.94 & 0.88 & 0.89 & 0.083 & 0.68 \\
N yield, kg/d & 0.148 & 0.139 & 0.139 & 0.0130 & 0.68 \\
As \% of N intake & 22.3 & 22.9 & 22.3 & 1.68 & 0.86 \\
ECM yield, ${ }^{2} \mathrm{~kg} / \mathrm{d}$ & 30.6 & 28.6 & 28.7 & 2.37 & 0.48 \\
Milk lactose, \% & 4.43 & 4.55 & 4.44 & 0.133 & 0.23 \\
MUN, mg/100 mL & 17.8 & 17.1 & 16.6 & 1.11 & 0.62 \\
BW, kg & 682 & 683 & 678 & 43.6 & 0.79 \\
\hline
\end{tabular}

${ }^{1}$ Data are reported as least squares means; $\mathrm{n}=18$.

${ }^{2}$ Milk true protein yield $\div 6.38$.

${ }^{3} \mathrm{ECM}$ yield $=$ milk yield, $\mathrm{kg} / \mathrm{d} \times[0.327+(7.2 \times$ milk true protein, $\% \div 100)+(12.95 \times$ milk fat, $\% \div$ $100)]$.

$<0.001$ ) cis-9 18:1 content (Table 8). Ruminal administration of $\mathrm{CO}$ also reduced $(P<0.001)$ cis-9 $18: 1$ and increased $(P<0.001$ to 0.01$)$ cis-13 18:1, cis-15 18:1, trans-12 18:1, and trans-13,-14 18:1 concentrations. However, CO resulted in larger $(P=0.009)$ decreases in milk cis-9 18:1 content compared with LA, whereas concentrations of cis-16 18:1 and trans-16 18:1 were lower $(P<0.007$ to 0.04$)$ in milk on CO than LA.

Relative to the control, LA and $\mathrm{CO}$ increased $(P<$ 0.02 to 0.03 ) cis-9, trans-13 18:2, trans-10, cis-12 CLA, and trans-11, trans-13 CLA and decreased $(P<0.001$ to 0.04) cis-9, cis-12 18:2, and trans-9, trans-11 CLA concentrations (Table 9 ). Furthermore, LA enhanced ( $P$ $<0.02$ to 0.03) milk cis-9, trans-14 18:2 and trans-10, trans-12 CLA compared with the control, whereas milk cis-9, trans-14 18:2 content tended $(P=0.07)$ to be higher for $\mathrm{CO}$ than the control. Changes in trans-10, trans-12 CLA were not significant $(P=0.69)$.

Ruminal administration of LA resulted in marginal increases in milk fat LA and cis-9 12:1 secretion of 42.4 and $0.74 \mathrm{~g} / \mathrm{d}$, respectively, associated with a mean efficiency of LA transfer from the rumen into milk of 18.0\%. For CO, 17.0 and $15.0 \%$ of LA and MA administered in the rumen (229 and $99.5 \mathrm{~g} / \mathrm{d}$, respectively) was apparently recovered in milk fat triacylglycerides.

Cumulative 14-d ammonia emissions from manure did not differ $(P=0.21$ to 0.95$)$ among treatments (Figure 9).

\section{DISCUSSION}

The inhibitory effects of free or esterified FA on the ruminal microbial ecosystem have been well documented. In general, short-chain, unsaturated, and free FA are more toxic to ruminal bacteria than longchain, saturated, and esterified FA (Henderson, 1973;
Palmquist and Jenkins, 1980; Nagaraja et al., 1997). Medium-chain saturated FA, specifically LA, are known to be particularly toxic to ruminal protozoa. Work by Sutton et al. (1983), Machmüler and Kreuzer (1999), and Dohme et al. (2001) and from our laboratory (Hristov et al., 2004a,b) has consistently shown a strong inhibitory effect of LA on ruminal ciliates. Thus, the over $80 \%$ decrease in protozoal counts observed for LA and $\mathrm{CO}$ in this experiment is not surprising. Similar to our previous observations (Hristov et al., 2001, 2004b) and numerous other reports, Entodinium was the main genus, constituting more than $95 \%$ of the total protozoal counts in the rumen of the cows. Of the other genera studied, only Dasytricha spp. were significantly decreased by LA and CO (the effect on Isotricha spp. did not reach statistical significance). The mode of application, however, appears to have a significant impact on the effectiveness of LA (or CO) as defaunating agent. For example, Faciola et al. (2005) reported that LA applied to the TMR was not as effective in reducing protozoal counts as LA administered directly into the rumen as a pulse dose. In this latter study, LA fed with the TMR at $240 \mathrm{~g} / \mathrm{d}(0.96 \%$ of DMI) resulted in a marginal $32 \%$ reduction in total protozoal counts, compared with a $91 \%$ reduction achieved with 1\% LA (as sodium laurate) when cows were treated intraruminally (Hristov et al., 2004b). Significantly higher levels of LA ( $4 \%$ of DMI) were required to achieve high reduction in protozoal counts when the application was through the TMR (Faciola et al., 2008). A natural explanation for this phenomenon is the likely greater ruminal concentration of LA achieved immediately following a pulse-dose. If fed through the TMR, LA would enter the rumen at a much slower rate and concentrations at any given time after feeding would likely be significantly lower compared with pulse-dosing. This differ- 


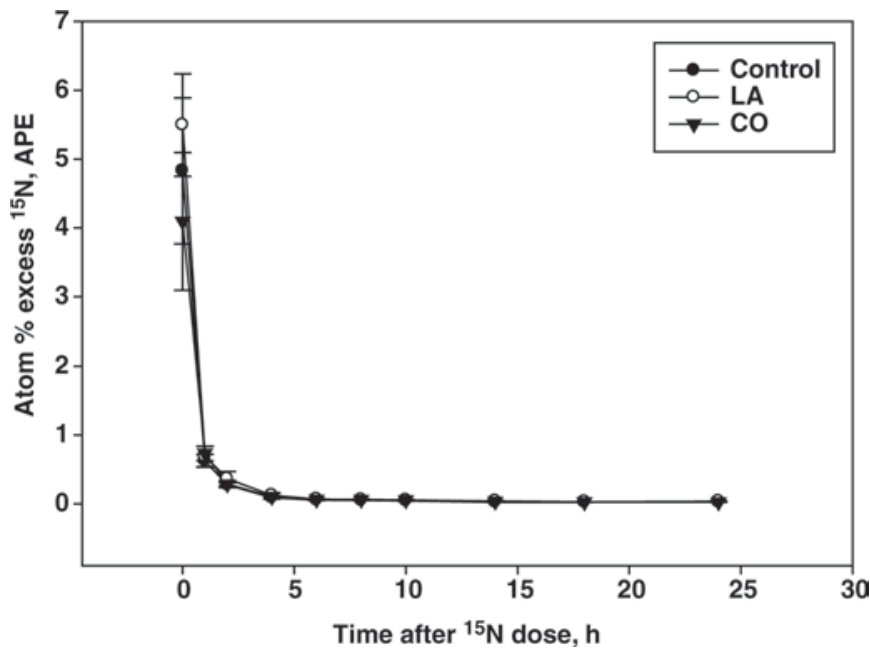

Figure 4. Effect of lauric acid (LA) and coconut oil (CO) on ${ }^{15} \mathrm{~N}$-enrichment of ruminal ammonia $\mathrm{N}$ in dairy cows (means $\pm \mathrm{SE} ; \mathrm{n}$ $=180$ ). Overall treatment effect, $P=0.58$; treatment $\times$ time interaction, $P=0.93$

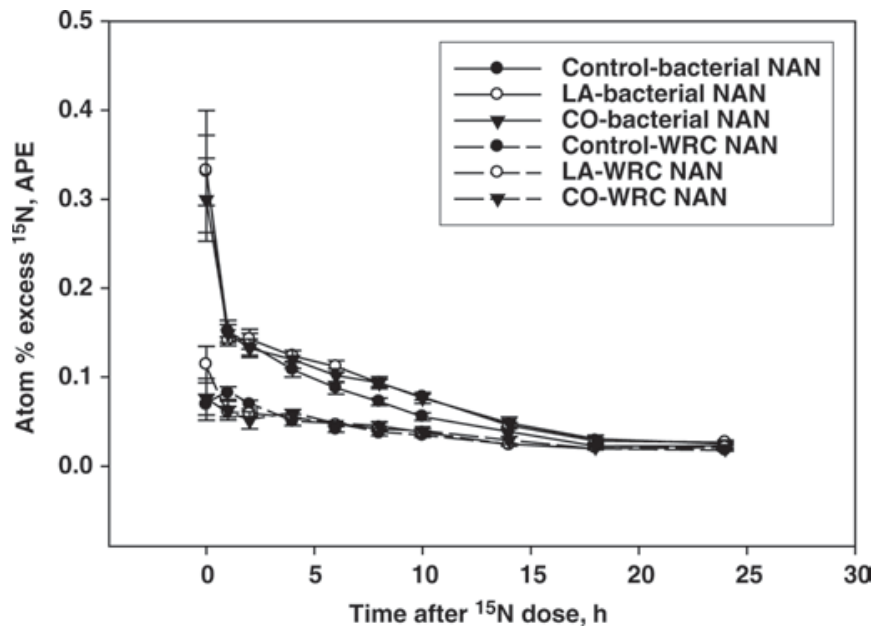

Figure 5. Effect of lauric acid (LA) and coconut oil (CO) on ${ }^{15} \mathrm{~N}$-enrichment of ruminal bacterial $(\mathrm{n}=180)$ and WRC (whole ruminal contents; $\mathrm{n}=150) \mathrm{NAN}$ in dairy cows (means $\pm \mathrm{SE}$ ). Overall treatment effect, $P=0.81$ and 0.60 ; treatment $\times$ time interaction, $P$ $=0.99$ and 0.03 , respectively.

Table 6. Effect of lauric acid (LA) and coconut oil (CO) on ${ }^{15} \mathrm{~N}$ enrichment of various $\mathrm{N}$ pools and ${ }^{15} \mathrm{~N}$ calculations in dairy cows ${ }^{1}$

\begin{tabular}{|c|c|c|c|c|c|}
\hline Item & Control & LA & $\mathrm{CO}$ & SEM & $P$-value \\
\hline${ }^{15} \mathrm{~N}$ enrichment of $\mathrm{NH}_{3} \mathrm{~N}, \mathrm{APE}^{2}$ & 0.603 & 0.694 & 0.547 & 0.1135 & $0.58^{3}$ \\
\hline${ }^{15} \mathrm{~N}$ enrichment of BN, APE & 0.103 & 0.113 & 0.108 & 0.0109 & $0.81^{3}$ \\
\hline${ }^{15} \mathrm{~N}$ enrichment of WRC, APE & 0.043 & 0.049 & 0.045 & 0.0040 & $0.60^{3}$ \\
\hline $\mathrm{AUC},{ }^{4} \mathrm{NH}_{3} \mathrm{~N}$ & 3.59 & 4.56 & 3.68 & 0.537 & 0.33 \\
\hline $\mathrm{AUC}, \mathrm{BN}$ & $1.48^{\mathrm{b}}$ & $1.77^{\mathrm{a}}$ & $1.76^{\mathrm{a}}$ & 0.104 & 0.003 \\
\hline AUC, MPN & 0.83 & 0.81 & 0.83 & 0.047 & 0.91 \\
\hline MPN from BN, ${ }^{8} \%$ & $56.4^{\mathrm{a}}$ & $45.9^{\mathrm{b}}$ & $48.2^{\mathrm{ab}}$ & 3.08 & $0.05^{9}$ \\
\hline MPN from $\mathrm{NH}_{3} \mathrm{~N},{ }^{10} \%$ & 23.3 & 19.7 & 24.2 & 2.63 & 0.44 \\
\hline Irreversible loss of ruminal $\mathrm{NH}_{3} \mathrm{~N}, \mathrm{~g} N / \mathrm{d}$ & 377 & 319 & 379 & 39.6 & 0.38 \\
\hline As $\%$ of $\mathrm{N}$ intake & 57 & 54 & 65 & 9.4 & 0.46 \\
\hline Ruminal $\mathrm{NH}_{3} \mathrm{~N}$ flux, g/d & $342^{\mathrm{a}}$ & $254^{\mathrm{b}}$ & $224^{\mathrm{b}}$ & 44.2 & 0.006 \\
\hline As $\%$ of $\mathrm{N}$ intake & $51^{\mathrm{a}}$ & $42^{\mathrm{ab}}$ & $35^{\mathrm{b}}$ & 6.12 & $0.02^{11}$ \\
\hline
\end{tabular}

${ }^{\mathrm{a}, \mathrm{b}}$ Within a row, means without a common superscript letter differ $(P<0.05)$.

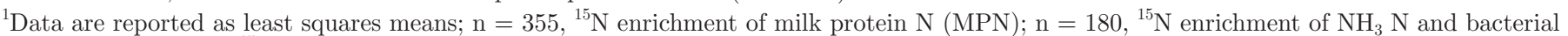
NAN (BN); $\mathrm{n}=150,{ }^{15} \mathrm{~N}$ enrichment of whole ruminal contents (WRC) $\mathrm{N}$; and $\mathrm{n}=18$, all other variables.

${ }^{2} \mathrm{APE}=$ atom percent excess.

${ }^{3}$ Whole ruminal contents $\mathrm{N}$ treatment $\times$ time interaction, $P=0.03$ (LA vs. control and $\mathrm{CO}$ at $0 \mathrm{~h}, P<0.001$ and $P=0.002$, respectively); all other treatment $\times$ time interactions, $P=0.56$ to 0.99

${ }^{4}$ Area under the ${ }^{15} \mathrm{~N}$ curve $(\mathrm{AUC})=\mathrm{APE} \times \mathrm{h}$.

${ }^{5}$ Calculated as $\left(\mathrm{AUC}_{\mathrm{WRC}} \div \mathrm{AUC}_{\text {rumen bacteria }}\right) \times 100$.

${ }^{6}$ Control vs. CO, $P=0.08$; control vs. LA, $P=0.056$.

${ }^{7}$ Calculated as $\left(\mathrm{AUC}_{\text {rumen bacteria }} \div \mathrm{AUC}_{\text {rumen ammonia }}\right) \times 100$.

${ }^{8}$ Calculated as $\left(\mathrm{AUC}_{\text {milk protein }} \div \mathrm{AUC}_{\text {rumen bacteria }}\right) \times 100$.

${ }^{9}$ Control vs. $\mathrm{CO}, P=0.06$.

${ }^{10}$ Calculated as $\left(\mathrm{AUC}_{\text {milk protein }} \div \mathrm{AUC}_{\text {rumen ammonia }}\right) \times 100$.

${ }^{11}$ Control vs. LA, $P=0.07$.

${ }^{12}$ Proportion of the irreversible loss of ammonia $\mathrm{N}$ leaving the rumen as microbial N. Calculated as [(MN flow $\times$ proportion of bacterial $\mathrm{N}$ derived from ammonia $\mathrm{N}) \div$ irreversible loss of ammonia $\mathrm{N}] \times 100$. 


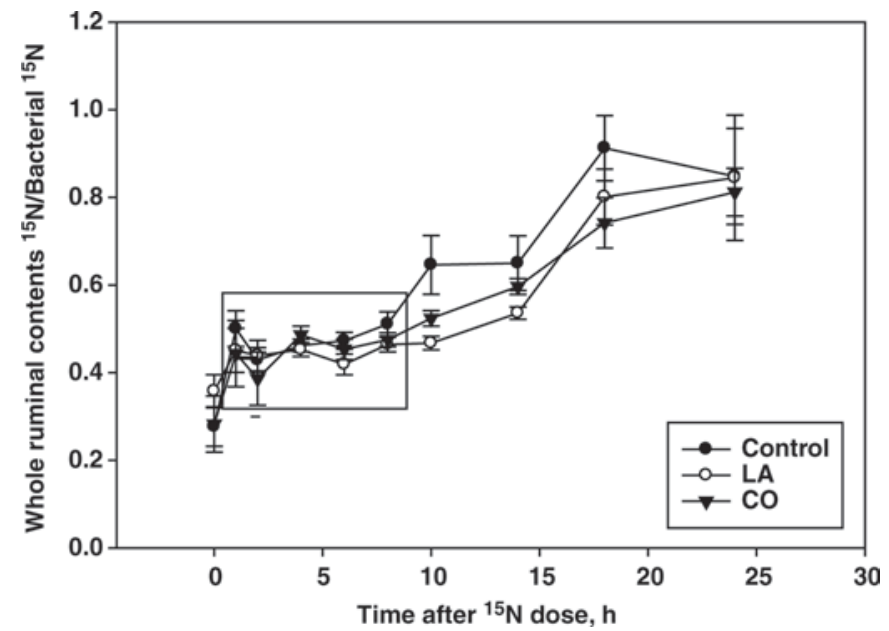

Figure 6. ${ }^{15} \mathrm{~N}$-enrichment of whole ruminal contents as proportion of ${ }^{15} \mathrm{~N}$-enrichment of bacterial $\mathrm{N}$ in dairy cows treated with lauric acid (LA) or coconut oil (CO; means $\pm \mathrm{SE} ; \mathrm{n}=150)$. Points in the rectangle ( 1 to $8 \mathrm{~h}$ posttreatment, $\mathrm{n}=73$ ) were used to estimate the proportion of microbial $\mathrm{N}$ in whole ruminal contents $(0.48,0.45$, and 0.45 , control, LA, and CO, respectively). Main effects of treatment, $P$ $=0.64$, and time, $P=0.14$; treatment $\times$ time interaction, $P=0.90$.

ence in LA concentration after treatment would explain the different response to LA when dosed intraruminally versus TMR feeding.

The ruminal effects observed in this experiment differed from our previous in vivo work (Hristov et al., 2004b). The form of LA in this latter study was sodium laurate, but LA and LA-Na should have similar effects in the rumen (Faciola et al., 2004). Ammonia concentration in ruminal fluid was significantly reduced by both $\mathrm{LA}$ and $\mathrm{CO}$ in the current experiment, whereas LA-Na did not affect ammonia concentrations in Hristov et

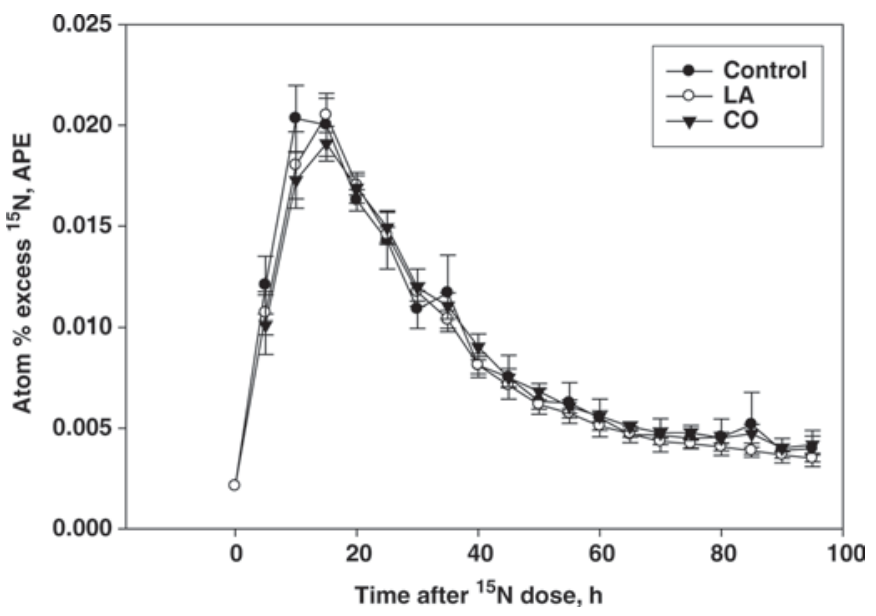

Figure 7. Effect of lauric acid (LA) and coconut oil (CO) on ${ }^{15} \mathrm{~N}$-enrichment of milk protein $\mathrm{N}$ in dairy cows (means $\pm \mathrm{SE} ; \mathrm{n}=$ $355)$. Overall treatment effect, $P=0.76$; treatment $\times$ time interaction, $P=0.95$. al. (2004b). Reduced ammonia concentration, likely resulting from reduced ammonia production, is typically reported for defaunated or animals with reduced rumen fauna. This a consequence of reduced proteolysis of bacterial protein and perhaps also plant proteins as protozoa possess protease activities (Williams and Coleman, 1992). The slightly lower TFAA concentration with LA and $\mathrm{CO}$ supports this hypothesis. Unlike results from Hristov et al. (2004b), LA significantly increased propionate concentration in the current experiment. The effect of defaunation on VFA and acetate:propionate ratio has not been consistent (Williams and Coleman, 1992). As suggested by Williams and Coleman (1992), the effect of defaunation on propionate concentration (and presumably production) is likely not a direct effect of decreased protozoal counts, but an indirect effect by the defaunating agent on ruminal bacteria. Henderson (1973) did not report inhibitory effects of LA and MA on Selenomonas ruminantium (oleic acid appeared to be the only inhibitory FA), which is the single most important rumen bacterium involved in decarboxylation of succinate to propionate (Wolin and Miller, 1988). It is likely that in studies in which defaunation resulted in increased propionate concentration (like the present experiment), the defaunating agent inhibited bacteria and protozoa that are not involved in propionate production, thus indirectly promoting the growth of species such as $S$. ruminantium that are central to propionic acid production in the rumen. In-

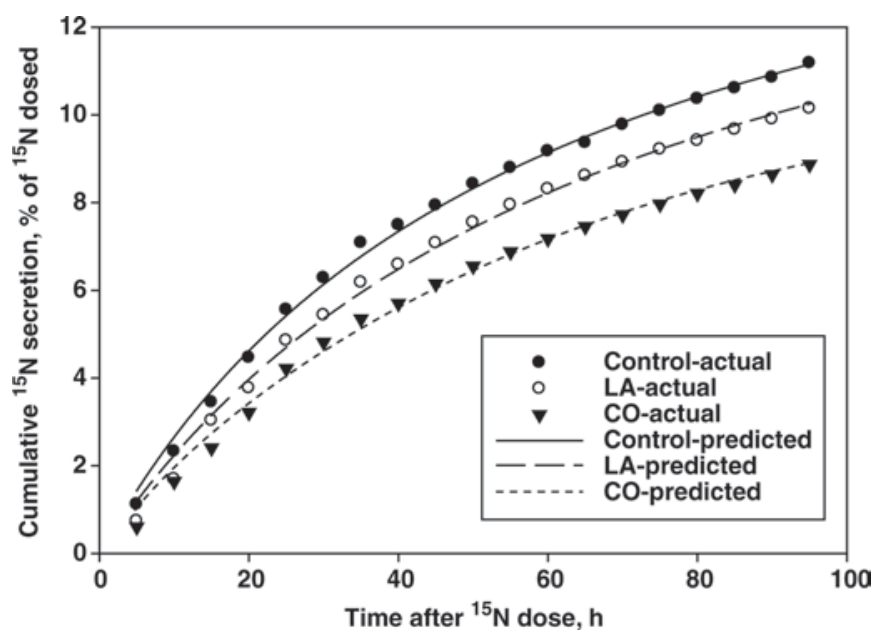

Figure 8. Effect of lauric acid (LA) and coconut oil (CO) on cumulative secretion of ${ }^{15} \mathrm{~N}$ in milk protein (as percentage of ${ }^{15} \mathrm{~N}$ dosed intraruminally). Symbols are measured and lines are predicted values (single rectangular 2-parameter hyperbola model). Theoretical maximum of ${ }^{15} \mathrm{~N}$ secreted in milk (as \% of dosed; estimate \pm approximate $\mathrm{SE} ; \mathrm{n}=114): 17.9 \pm 2.78,17.7 \pm 2.51$, and $15.6 \pm 2.68$, for control, LA, and CO, respectively $(P=0.54$ to 0.96$)$. Significant differences between ${ }^{15} \mathrm{~N}$ secretion lines: control vs. LA, $P=0.04$; control vs. $\mathrm{CO}$, $P<0.001 ;$ LA vs. CO, $P=0.01$. 
Table 7. Effect of lauric acid (LA) and coconut oil (CO) on milk fatty acid composition (g/100 g total fatty acids) in dairy cows ${ }^{1}$

\begin{tabular}{|c|c|c|c|c|c|}
\hline Fatty acid & Control & LA & $\mathrm{CO}$ & SEM & $P$-value \\
\hline 4:0 & $3.29^{\mathrm{a}}$ & $2.99^{\mathrm{b}}$ & $3.14^{\mathrm{ab}}$ & 0.179 & 0.015 \\
\hline $6: 0$ & $2.13^{\mathrm{a}}$ & $1.90^{\mathrm{b}}$ & $1.90^{\mathrm{b}}$ & 0.040 & 0.001 \\
\hline $8: 0$ & $1.30^{\mathrm{a}}$ & $1.17^{\mathrm{b}}$ & $1.15^{\mathrm{b}}$ & 0.016 & $<0.001$ \\
\hline $10: 0$ & $3.25^{\mathrm{a}}$ & $2.99^{\mathrm{b}}$ & $2.93^{\mathrm{b}}$ & 0.075 & $<0.001$ \\
\hline cis-9 10:1 & $0.30^{\mathrm{a}}$ & $0.27^{\mathrm{b}}$ & $0.25^{\mathrm{b}}$ & 0.008 & 0.006 \\
\hline 11-cyclo 11:0 & 0.01 & 0.02 & 0.02 & 0.001 & 0.26 \\
\hline $12: 0$ & $4.08^{\mathrm{b}}$ & $9.06^{\mathrm{a}}$ & $8.54^{\mathrm{a}}$ & 0.160 & $<0.001$ \\
\hline cis-9 $12: 1$ & $0.10^{\mathrm{b}}$ & $0.19^{\mathrm{a}}$ & $0.17^{\mathrm{a}}$ & 0.006 & $<0.001$ \\
\hline trans-9 12:1 & $0.09^{\mathrm{b}}$ & $0.19^{\mathrm{a}}$ & $0.18^{\mathrm{a}}$ & 0.007 & $<0.001$ \\
\hline $13: 0$ iso & $0.03^{\mathrm{a}}$ & $0.02^{\mathrm{b}}$ & $0.02^{\mathrm{b}}$ & 0.004 & 0.006 \\
\hline 13:0 anteiso & 0.01 & 0.01 & 0.01 & 0.000 & 0.21 \\
\hline 14:0 & $12.3^{\mathrm{b}}$ & $12.5^{\mathrm{b}}$ & $14.7^{\mathrm{a}}$ & 0.128 & $<0.001$ \\
\hline $14: 0$ iso & $0.11^{\mathrm{a}}$ & $0.08^{\mathrm{b}}$ & $0.08^{\mathrm{b}}$ & 0.017 & 0.011 \\
\hline cis-9 $14: 1$ & $0.96^{\mathrm{b}}$ & $1.06^{\mathrm{b}}$ & $1.24^{\mathrm{a}}$ & 0.031 & 0.002 \\
\hline trans-9 14:1 & 0.02 & 0.02 & 0.02 & 0.001 & 0.19 \\
\hline $15: 0$ & $1.47^{\mathrm{ab}}$ & $1.53^{\mathrm{a}}$ & $1.31^{\mathrm{b}}$ & 0.046 & 0.06 \\
\hline $15: 0$ iso & $0.20^{\mathrm{a}}$ & $0.19^{\mathrm{ab}}$ & $0.17^{\mathrm{b}}$ & 0.018 & 0.04 \\
\hline 15:0 anteiso & $0.40^{\mathrm{a}}$ & $0.39^{\mathrm{a}}$ & $0.32^{\mathrm{b}}$ & 0.030 & 0.003 \\
\hline cis-9 15:1 & 0.02 & 0.02 & 0.02 & 0.001 & 0.54 \\
\hline trans-5 15:1 & $0.08^{\mathrm{a}}$ & $0.07^{\mathrm{b}}$ & $0.06^{\mathrm{b}}$ & 0.003 & 0.008 \\
\hline trans-6 15:1 & 0.01 & 0.01 & 0.01 & 0.001 & 0.93 \\
\hline $16: 0$ & $32.6^{\mathrm{a}}$ & $30.9^{\mathrm{b}}$ & $30.8^{\mathrm{b}}$ & 0.259 & 0.003 \\
\hline $16: 0$ iso & $0.24^{\mathrm{a}}$ & $0.18^{\mathrm{b}}$ & $0.20^{\mathrm{ab}}$ & 0.028 & 0.05 \\
\hline cis-9 16:1 & 1.52 & 1.63 & 1.65 & 0.133 & 0.38 \\
\hline cis-11 16:1 & $0.02^{\mathrm{c}}$ & $0.04^{\mathrm{b}}$ & $0.06^{\mathrm{a}}$ & 0.007 & 0.004 \\
\hline cis-13 16:1 & $0.15^{\mathrm{a}}$ & $0.14^{\mathrm{ab}}$ & $0.13^{\mathrm{b}}$ & 0.014 & 0.04 \\
\hline trans- $6,-7,-8 \quad 16: 1$ & 0.04 & 0.04 & 0.05 & 0.006 & 0.18 \\
\hline trans-9 $16: 1$ & $0.03^{\mathrm{b}}$ & $0.03^{\mathrm{b}}$ & $0.04^{\mathrm{a}}$ & 0.005 & 0.021 \\
\hline trans-12 16:1 & $0.18^{\mathrm{b}}$ & $0.23^{\mathrm{a}}$ & $0.24^{\mathrm{a}}$ & 0.010 & 0.006 \\
\hline trans-13 16:1 & $0.01^{\mathrm{b}}$ & $0.02^{\mathrm{a}}$ & $0.03^{\mathrm{a}}$ & 0.003 & 0.007 \\
\hline$\Sigma$ cis $16: 1$ & 1.70 & 1.82 & 1.85 & 0.127 & 0.31 \\
\hline$\sum$ trans $16: 1$ & $0.26^{\mathrm{b}}$ & $0.32^{\mathrm{a}}$ & $0.36^{\mathrm{a}}$ & 0.020 & 0.009 \\
\hline$\Sigma 16: 1$ & 1.95 & 2.14 & 2.21 & 0.146 & 0.14 \\
\hline cis-9, cis-12 16:2 & 0.01 & 0.01 & 0.01 & 0.001 & 0.147 \\
\hline $17: 0$ & $0.71^{\mathrm{a}}$ & $0.64^{\mathrm{b}}$ & $0.55^{\mathrm{c}}$ & 0.014 & $<0.001$ \\
\hline 17:0 iso & $0.27^{\mathrm{a}}$ & $0.27^{\mathrm{a}}$ & $0.25^{\mathrm{b}}$ & 0.012 & 0.06 \\
\hline 17:0 anteiso & $0.19^{\mathrm{a}}$ & $0.16^{\mathrm{b}}$ & $0.14^{\mathrm{c}}$ & 0.015 & 0.001 \\
\hline 18:0 & $9.22^{\mathrm{a}}$ & $7.57^{\mathrm{b}}$ & $6.94^{\mathrm{b}}$ & 0.361 & 0.001 \\
\hline $18: 0$ iso & 0.04 & 0.04 & 0.04 & 0.002 & 0.23 \\
\hline$\Sigma$ cis $18: 1$ & $16.0^{\mathrm{a}}$ & $14.8^{\mathrm{b}}$ & $13.8^{\mathrm{c}}$ & 0.222 & $<0.001$ \\
\hline$\Sigma$ trans $18: 1$ & $2.83^{\mathrm{b}}$ & $3.35^{\mathrm{ab}}$ & $3.79^{\mathrm{a}}$ & 0.392 & 0.14 \\
\hline$\sum 18: 1$ & $18.8^{\mathrm{a}}$ & $18.1^{\mathrm{ab}}$ & $17.6^{\mathrm{b}}$ & 0.336 & 0.11 \\
\hline$\Sigma 18: 2^{2}$ & $2.73^{\mathrm{a}}$ & $2.50^{\mathrm{b}}$ & $2.46^{\mathrm{b}}$ & 0.051 & 0.006 \\
\hline$\Sigma$ CLA & $0.36^{\mathrm{b}}$ & $0.42^{\mathrm{a}}$ & $0.41^{\mathrm{ab}}$ & 0.040 & 0.12 \\
\hline $18: 3 \mathrm{n}-3$ & $0.40^{\mathrm{a}}$ & $0.31^{\mathrm{b}}$ & $0.28^{\mathrm{b}}$ & 0.024 & 0.001 \\
\hline $18: 3 n-6$ & 0.03 & 0.04 & 0.03 & 0.004 & 0.21 \\
\hline $19: 0$ & 0.09 & 0.11 & 0.11 & 0.011 & 0.41 \\
\hline $20: 0$ & $0.15^{\mathrm{a}}$ & $0.13^{\mathrm{b}}$ & $0.11^{\mathrm{c}}$ & 0.005 & 0.001 \\
\hline cis-6,-7,-8 20:1 & 0.07 & 0.06 & 0.05 & 0.010 & 0.43 \\
\hline cis-9 20:1 & $0.09^{\mathrm{a}}$ & $0.09^{\mathrm{a}}$ & $0.07^{\mathrm{b}}$ & 0.004 & 0.034 \\
\hline cis-11 20:1 & $0.018^{\mathrm{a}}$ & $0.023^{\mathrm{ab}}$ & $0.024^{\mathrm{b}}$ & 0.0026 & 0.05 \\
\hline$\Sigma 20: 1$ & 0.18 & 0.17 & 0.14 & 0.011 & 0.21 \\
\hline $20: 2 \mathrm{n}-6$ & $0.034^{\mathrm{a}}$ & $0.031^{\mathrm{b}}$ & $0.030^{\mathrm{b}}$ & 0.0012 & 0.003 \\
\hline $20: 3 n-3$ & 0.01 & 0.01 & 0.01 & 0.001 & 0.81 \\
\hline $20: 3$ n-6 & 0.11 & 0.10 & 0.10 & 0.006 & 0.39 \\
\hline $20: 4$ n-3 & 0.02 & 0.02 & 0.02 & 0.001 & 0.68 \\
\hline $20: 4 n-6$ & 0.15 & 0.14 & 0.13 & 0.024 & 0.18 \\
\hline $20: 5 n-3$ & 0.04 & 0.04 & 0.04 & 0.004 & 0.31 \\
\hline $22: 0$ & $0.05^{\mathrm{a}}$ & $0.04^{\mathrm{b}}$ & $0.03^{\mathrm{c}}$ & 0.002 & $<0.001$ \\
\hline$\Sigma 22: 1$ & $0.012^{\mathrm{a}}$ & $0.011^{\mathrm{ab}}$ & $0.008^{\mathrm{b}}$ & 0.0011 & 0.05 \\
\hline $22: 4$ n- 6 & $0.023^{\mathrm{a}}$ & $0.018^{\mathrm{b}}$ & $0.018^{\mathrm{b}}$ & 0.0044 & 0.035 \\
\hline $22: 5$ n-3 & 0.06 & 0.05 & 0.05 & 0.009 & 0.14 \\
\hline $22: 5 \mathrm{n}-6$ & $0.023^{\mathrm{a}}$ & $0.015^{\mathrm{b}}$ & $0.009^{\mathrm{c}}$ & 0.0036 & $<0.001$ \\
\hline $23: 0$ & $0.029^{\mathrm{a}}$ & $0.024^{\mathrm{b}}$ & $0.019^{\mathrm{c}}$ & 0.0025 & $<0.001$ \\
\hline $24: 0$ & $0.032^{\mathrm{a}}$ & $0.026^{\mathrm{b}}$ & $0.018^{\mathrm{c}}$ & 0.0019 & $<0.001$ \\
\hline
\end{tabular}


Table 7 (Continued). Effect of lauric acid (LA) and coconut oil (CO) on milk fatty acid composition (g/100 $\mathrm{g}$ total fatty acids) in dairy cows ${ }^{1}$

\begin{tabular}{lccccc}
\hline Fatty acid & Control & LA & CO & SEM & $P$-value \\
\hline $26: 0$ & $0.012^{\mathrm{a}}$ & $0.009^{\mathrm{b}}$ & $0.007^{\mathrm{c}}$ & 0.0010 & $<0.001$ \\
$\Sigma$ unidentified & $0.77^{\mathrm{a}}$ & $0.74^{\mathrm{ab}}$ & $0.67^{\mathrm{b}}$ & 0.027 & 0.12 \\
$\Sigma$ saturated fatty acids & 72.5 & 73.1 & 73.7 & 0.414 & 0.24 \\
$\sum$ trans fatty acids & $3.70^{\mathrm{b}}$ & $4.48^{\mathrm{ab}}$ & $4.99^{\mathrm{a}}$ & 0.465 & 0.09 \\
$\Sigma$ MUFA $^{3}$ & 22.8 & 22.5 & 22.1 & 0.480 & 0.62 \\
$\Sigma$ PUFA $^{3}$ & $3.99^{\mathrm{a}}$ & $3.70^{\mathrm{b}}$ & $3.60^{\mathrm{b}}$ & 0.092 & 0.008 \\
\hline
\end{tabular}

${ }^{\mathrm{a}-\mathrm{c}}$ Within a row, means without a common superscript letter differ $(P<0.05)$.

${ }^{1}$ Data are presented as least squares means; $\mathrm{n}=18$.

${ }^{2}$ Sum of 18:2 excluding isomers of CLA.

${ }^{3} \mathrm{MUFA}=$ monounsaturated fatty acids; PUFA $=$ polyunsaturated fatty acids.

creases in ruminal propionate concentration because of LA or CO have been reported previously (Rindsig and Schultz, 1974; Sutton et al., 1983; Ajisaka et al., 2002; Yabuuchi et al., 2006). Defaunation often decreases rumen butyrate concentration (Williams and Coleman, 1992). Ruminal protozoa produce butyrate as an end product of carbohydrate fermentation (Williams and Coleman, 1997), but the effect of LA and CO in the present study was most likely a result of inhibition of both protozoa and important butyrate producers in the rumen, such as Butyrivibrio fibrisolvens. Henderson (1973), for example, reported inhibitory effect of $0.5 \mathrm{~g}$ of $\mathrm{LA} / \mathrm{L}$ (which would correspond to about $50 \mathrm{~g} / \mathrm{cow}$ daily dose, assuming a 100-L rumen volume) on $B$. fibrisolvens. Similar to our previous observations (Hristov et al., 2004b), carboxymethylcellulase activity of ruminal fluid was suppressed by LA. Fibrolytic bacteria are among the most sensitive to inhibition by dietary fats (Palmquist and Jenkins, 1980; Nagaraja et al., 1997) and Ruminococcus spp. was one of the most affected by LA species in the study by Henderson (1973). Suppression of endoglucanase activity, total bacterial counts, and cellulolytic and amylolytic species with 10\% (DM basis) supplementation of $\mathrm{CO}$ was reported by Dong et al. (1997; RUSITEC). The numerical decrease in total tract apparent NDF digestibility with $\mathrm{CO}(P=0.13)$ also provides evidence for potential inhibitory effects of $\mathrm{CO}$ on rumen fibrolytic bacteria, whereas other studies have shown that CO depresses ruminal and total tract fiber digestion (Sutton et al., 1983).

One of the most studied properties of MCFA is the inhibitory effect on ruminal methanogenesis (Machmüller, 2006). In this experiment, LA had no effect on methane production rate. Variability among cows in methane concentration (not shown) and production rate (evident by the SE on Figure 2) was large, particularly for the control (SA) and LA. Lauric acid did not elicit any substantial effect on methane production postfeeding or reduce peak methane formation in the rumen. This is in contrast to several reports in which LA has been shown to inhibit methanogens and methanogenesis in the rumen (Blaxter and Czerkawski, 1966; Ajisaka et al., 2002; Machmüller et al., 2002; Soliva et al., 2003). However, other studies have also found little evidence of LA suppressing rumen methanogenesis (Dohme et al., 2001). Early studies established that the maximum inhibition of Methanobacterium ruminantium by LA was about $50 \%$ (relative to the control), compared with $68 \%$ at the highest level of MA and $72 \%$ to cis-9 18:1 (Henderson, 1973). The strong inhibition of methane production rates by $\mathrm{CO}$ in the current study is rather difficult to reconcile, because CO contains $46 \%$ LA, and MA has been reported to be an effective methane suppressor in some (Henderson, 1973; Machmüller et al., 2003), but not all studies (Soliva et al., 2004). Inclusion of MA in the diet at $5 \%$ of DM was shown to induce a $36 \%$ decrease in methane production in lactating cows (Odongo et al., 2007), but this amount of MA, corresponding to about $1.25 \mathrm{~kg} / \mathrm{d}$, is much higher than that evaluated in the current study. There is evidence to suggest that MA may enhance the methane mitigating effect of LA. Soliva et al. (2003, 2004) demonstrated that mixtures of LA and MA have similar methane depressing effects compared with LA alone, with the most effective ratio of LA:MA being close to that in CO. Several studies have shown that CO, which contains about 18 to $20 \%$ MA, consistently decreases rumen methanogenesis (Dohme et al., 1999; Jordan et al., 2006; Yabuuchi et al., 2006). It is probable that the associative effects of LA and MA, in addition to the high amount of total MCFA administered, can explain the suppression of methanogenesis by $\mathrm{CO}$, whereas LA was ineffective, in the present study.

Despite LA and CO decreasing the protozoal numbers in the rumen, methanogen-specific DGGE did not reveal any treatment specific-banding patterns. This finding is in contrast with dot-blot analyses of the bovine ruminal fluid and its protozoal fraction with taxon-specific $16 \mathrm{~S}$ rRNA probes, implying that protozoal-associated methanogens account for up to 
Table 8. Effect of lauric acid (LA) and coconut oil (CO) on milk 18:1 content (g/100 g total fatty acids) in dairy cows ${ }^{1}$

\begin{tabular}{|c|c|c|c|c|c|}
\hline Fatty acid & Control & LA & $\mathrm{CO}$ & SEM & $P$-value \\
\hline cis-9 $18: 1^{2}$ & $14.8^{\mathrm{a}}$ & $13.3^{\mathrm{b}}$ & $12.4^{\mathrm{c}}$ & 0.251 & $<0.001$ \\
\hline cis-11 18:1 & 0.71 & 0.78 & 0.72 & 0.025 & 0.20 \\
\hline cis-12 18:1 & 0.32 & 0.40 & 0.40 & 0.036 & 0.23 \\
\hline cis-13 18:1 & $0.05^{\mathrm{b}}$ & $0.08^{\mathrm{a}}$ & $0.09^{\mathrm{a}}$ & 0.008 & 0.002 \\
\hline cis-15 18:1 & $0.06^{\mathrm{b}}$ & $0.10^{\mathrm{a}}$ & $0.11^{\mathrm{a}}$ & 0.011 & 0.01 \\
\hline cis-16 18:1 & $0.06^{\mathrm{b}}$ & $0.07^{\mathrm{a}}$ & $0.06^{\mathrm{b}}$ & 0.003 & 0.03 \\
\hline trans-4 18:1 & 0.02 & 0.02 & 0.02 & 0.001 & 0.32 \\
\hline trans-5 18:1 & 0.01 & 0.02 & 0.02 & 0.001 & 0.43 \\
\hline trans- $6,-7,-8$ 18:1 & 0.22 & 0.23 & 0.27 & 0.029 & 0.32 \\
\hline trans $-918: 1$ & 0.58 & 0.55 & 0.56 & 0.029 & 0.67 \\
\hline trans-10 18:1 & 0.40 & 0.55 & 1.02 & 0.280 & 0.26 \\
\hline trans-11 18:1 & 0.53 & 0.61 & 0.61 & 0.061 & 0.25 \\
\hline trans-12 $18: 1$ & $0.27^{\mathrm{b}}$ & $0.34^{\mathrm{a}}$ & $0.33^{\mathrm{a}}$ & 0.013 & 0.009 \\
\hline trans-13,-14 18:1 & $0.61^{\mathrm{b}}$ & $0.81^{\mathrm{a}}$ & $0.79^{\mathrm{a}}$ & 0.036 & $<0.001$ \\
\hline trans-16 $18: 1^{3}$ & $0.20^{\mathrm{ab}}$ & $0.22^{\mathrm{a}}$ & $0.18^{\mathrm{b}}$ & 0.015 & $0.02^{4}$ \\
\hline
\end{tabular}

${ }^{\mathrm{a}-\mathrm{c}}$ Within a row, means without a common superscript letter differ $(P<0.05)$.

${ }^{1}$ Data are presented as least squares means; $\mathrm{n}=18$.

${ }^{2}$ Contains trans-15 18:1 as a minor component.

${ }^{3}$ Co-elutes with cis-14 18:1.

${ }^{4}$ Control vs. LA, $P=0.06$.

$90 \%$ of the ruminal methanogen population (Sharp et al., 1998). Elimination of protozoa did not affect methane production from continuous culture fermenters modified to retain protozoa (Karnati et al., 2009a). Coconut oil did not appear to exhibit specific effects on ruminal methanogen populations even though it had the lowest methane production. Even though changes in DGGE methanogen banding profile have been detected in populations isolated from faunated or defaunated continuous culture, these were not associated with differences in methane production (Karnati et al., 2009b). Inoculation of sheep with an antimethanogen vaccine revealed that whereas methane production and the numbers of methanogens in the rumen determined by real-time PCR were not different, the diversity of rumen methanogens was significantly larger in response to the antimethanogen vaccine (Williams et al., 2009). Overall data are consistent with methane production in the rumen being less affected by methanogen abundance and the diversity of ruminal methanogen populations, compared with the accumulation of hydrogen in the rumen.

The microbial mass in the rumen was 10 to $15 \% \mathrm{nu}-$ merically lower and MNF was 13 (LA) to $27 \%$ (CO) lower with the experimental treatments compared with the control in this study. Most likely, this was due to depressed DMI (numerical differences) with LA and $\mathrm{CO}$ compared with the control, but a direct suppression of certain bacterial groups in the rumen cannot be excluded. Interestingly, Sylvester et al. (2005) using molecular techniques determined the protozoal population in the rumen to be between 5 and $13 \%$ of the total microbial $\mathrm{N}$ pool. If we assume that the decrease in the
MN pool reported in the current study (14\%, LA and $10 \%, \mathrm{CO}, \mathrm{AUC}$; similar estimates were derived using the steady-state ${ }^{15} \mathrm{~N}$ enrichment approach) is due only to the eradication of protozoa (i.e., no effect on rumen bacteria), then the protozoal $\mathrm{N}$ pool in the rumen can be estimated to represent from 12 [CO; example: $1 \div$ 0.83 (the reduction in protozoal counts) $\times 10 \%$ (the reduction in microbial $\mathrm{N}$ pool)] to $18 \%$ (LA) of the total MN pool. These estimates are similar to those of Sylvester et al. (2005) and are significantly lower than the conventional assumption that protozoa rep-

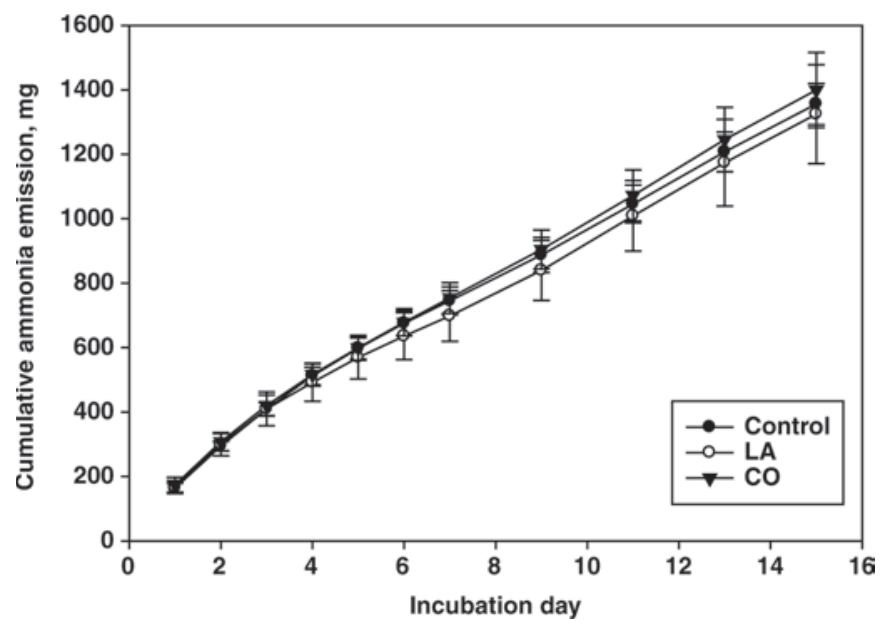

Figure 9. Effect of lauric acid (LA) and coconut oil (CO) on cumulative ammonia emission from dairy manure (means $\pm \mathrm{SE}$ ). End-point (d 15) cumulative ammonia emission $(\mathrm{n}=18 ; P=0.88): 1,355,1,324$, and 1,399 $\mathrm{mg}$ (control, LA, and CO, respectively). Regression analysis $(\mathrm{n}=198), P=0.21$ to 0.95 ; slope: 82,79 , and $84 \mathrm{mg}$ ammonia/d (respectively; $\mathrm{SEM}=4.35, P=0.38$ to 0.68 ). 
resent $50 \%$ or more of the total $\mathrm{MN}$ pool in the rumen (Jouany, 1996). The protozoal mass in the rumen can significantly vary, depending on diet and DMI (20 to $70 \%$ of the total microbial mass, according to Coleman, 1979). Our approach to estimate the microbial N pool in the rumen was based on 1) $\mathrm{AUC}-{ }^{15} \mathrm{~N}$ of bacterial and WRC N; and 2) the apparent steady-state enrichment of bacterial and WRC N between 1 and 8 h post- ${ }^{15} \mathrm{~N}$ dose. Both approaches gave similar estimates of about 49 (example with the control diet; approach 2) to $56 \%$ (approach 1) microbial $\mathrm{N}$ in the WRC N pool (Table 2). The ratios of WRC- ${ }^{15} \mathrm{~N}$ : bacterial- ${ }^{15} \mathrm{~N}$ (Figure 6) were constant within the 1-to-8-h sampling window, but rapidly increased thereafter approaching an equilibrium at $24 \mathrm{~h}$ (Figure 5). These data suggest that within a certain period of time, which may differ between studies, WRC- $-{ }^{15} \mathrm{~N}$ :bacterial $-{ }^{15} \mathrm{~N}$ ratio closely represents the proportion of MN in ruminal digesta, provided the assumption that ${ }^{15} \mathrm{~N}$ enrichment of the bacterial standard is representative of the ${ }^{15} \mathrm{~N}$ enrichment of $\mathrm{MN}$ holds true. The concept of estimating MNF from the rumen based on rumen sampling is well established (Hristov and Broderick, 1996; Hristov, 2007) and data from this experiment indicate that the mass of microbial $\mathrm{N}$ in ruminal contents can be reliably estimated from rumen sampling allowing predictions of MNF when used in conjunction with appropriate passage rate markers.

The effect and potential benefits of defaunation or reduced protozoal population on microbial protein synthesis and MNF from the rumen have been extensively discussed (Hristov and Jouany, 2005). Data from this and our previous in vivo study (Hristov et al., 2004b), however, did not show a positive effect of the reduced fauna on MNF in the rumen. As discussed (Hristov et al., 2004b), a potential inhibition of the bacterial population in the rumen can partially explain the observed lack of effect on MNF. Defaunating agents (including MCFA) are not protozoa-specific and can significantly and adversely affect the bacterial population in the rumen (Williams and Coleman, 1992). As indicated earlier, the decrease in MNF with LA and CO observed in the present experiment is most likely caused by the numerically lower DMI compared with the control. Undoubtedly, intake of DM/OM is the main dietary factor determining microbial protein synthesis in the rumen (Oldick et al., 1999) and the 2 to $2.5 \mathrm{~kg}$ lower DMI with LA and CO are enough to account for the lower MNF with these treatments.

Table 9. Effect of lauric acid (LA) and coconut oil (CO) on milk 18:2 content (mg/100 g of total fatty acids) in dairy cows ${ }^{1}$

\begin{tabular}{|c|c|c|c|c|c|}
\hline Fatty acid & Control & $\mathrm{LA}$ & $\mathrm{CO}$ & SEM & $P$-value \\
\hline cis-9, cis-12 18:2 & $2.26^{\mathrm{a}}$ & $1.92^{\mathrm{b}}$ & $1.87^{\mathrm{b}}$ & 0.082 & $<0.001$ \\
\hline cis-12, cis-15 18:2 & 0.06 & 0.05 & 0.04 & 0.009 & 0.31 \\
\hline cis-9, trans-13 18:2 $2^{2}$ & $0.14^{\mathrm{b}}$ & $0.19^{\mathrm{a}}$ & $0.18^{\mathrm{a}}$ & 0.014 & 0.02 \\
\hline cis-9, trans-14 18:2 & $0.05^{\mathrm{b}}$ & $0.06^{\mathrm{a}}$ & $0.06^{\mathrm{ab}}$ & 0.003 & $0.02^{3}$ \\
\hline trans-9, trans-12 18:2 & 0.01 & 0.01 & 0.02 & 0.004 & 0.26 \\
\hline cis-9, trans-12 18:2 & 0.06 & 0.06 & 0.06 & 0.004 & 0.60 \\
\hline trans-11, cis-15 18:2 & 0.04 & 0.07 & 0.13 & 0.034 & 0.17 \\
\hline trans-12, cis-15 18:2 & 0.07 & 0.07 & 0.07 & 0.003 & 0.90 \\
\hline trans-9, cis-12 18:2 & 0.04 & 0.04 & 0.05 & 0.003 & 0.84 \\
\hline cis-9, cis-11 $\mathrm{CLA}^{4}$ & 3.10 & 2.08 & 2.07 & 0.416 & 0.25 \\
\hline cis-10, cis-12 CLA & 0.84 & 0.28 & 0.42 & 0.307 & 0.53 \\
\hline cis-9, trans-11 CLA & 228 & 282 & 253 & 30.58 & 0.20 \\
\hline cis-11, trans-13 CLA & 1.10 & 2.44 & 1.65 & 0.557 & 0.33 \\
\hline cis/trans $12,14 \mathrm{CLA}$ & 1.19 & 1.28 & 1.47 & 0.272 & 0.65 \\
\hline cis/trans $13,15 \mathrm{CLA}$ & $4.31^{\mathrm{b}}$ & $6.22^{\mathrm{a}}$ & $6.48^{\mathrm{a}}$ & 0.505 & 0.04 \\
\hline trans-7, cis-9 CLA & 42.0 & 47.2 & 58.3 & 8.276 & 0.34 \\
\hline trans-8, cis-10 CLA & 10.4 & 9.91 & 8.08 & 0.796 & 0.24 \\
\hline trans-9, cis-11 CLA & 10.4 & 12.6 & 18.5 & 4.179 & 0.35 \\
\hline trans-10, cis-12 CLA & $5.68^{\mathrm{b}}$ & $10.1^{\mathrm{a}}$ & $9.98^{\mathrm{a}}$ & 0.953 & 0.03 \\
\hline trans-11, cis-13 CLA & 2.64 & 3.34 & 2.49 & 0.332 & 0.33 \\
\hline trans-7, trans-9 CLA & 1.99 & 2.33 & 2.41 & 0.372 & 0.67 \\
\hline trans-8, trans-10 CLA & 3.36 & 3.15 & 2.87 & 0.191 & 0.22 \\
\hline trans -9, trans-11 CLA & $17.1^{\mathrm{a}}$ & $13.7^{\mathrm{b}}$ & $13.1^{\mathrm{b}}$ & 1.079 & 0.04 \\
\hline trans-10, trans-12 CLA & $8.24^{\mathrm{b}}$ & $10.1^{\mathrm{a}}$ & $8.44^{\mathrm{b}}$ & 0.275 & 0.009 \\
\hline trans-11, trans-13 CLA & $8.49^{\mathrm{b}}$ & $11.2^{\mathrm{a}}$ & $11.0^{\mathrm{a}}$ & 0.582 & 0.02 \\
\hline trans-12, trans-14 CLA & 4.72 & 5.18 & 4.53 & 0.251 & 0.24 \\
\hline trans-13, trans-15 CLA & 0.39 & 1.03 & 0.67 & 0.180 & 0.12 \\
\hline
\end{tabular}

${ }^{\mathrm{ab}}$ Within a row, means without a common superscript letter differ $(P<0.05)$.

${ }^{1}$ Data are presented as least squares means; $\mathrm{n}=18$.

${ }^{2}$ Co-elutes with cis-10, trans-14 18:2.

${ }^{3}$ Control vs. $\mathrm{CO}, P=0.07$

${ }^{4} \mathrm{CLA}=$ conjugated linoleic acid. 
Ruminal ammonia flux, irreversible loss, and concentration in ruminal fluid data tend to suggest that LA and $\mathrm{CO}$ reduced amino acid deamination and possibly proteolysis in the rumen. Urinary $\mathrm{N}$ excretion also tended to be lower for $\mathrm{CO}$ whereas urinary $\mathrm{N}$ losses as a proportion of $\mathrm{N}$ intake were higher for LA compared with the control. Even though the amount of urinary urea excreted with cattle manure is the single most important factor influencing manure ammonia emissions (Ndegwa et al., 2008), the reduction in urinary $\mathrm{N}$ excretion with $\mathrm{CO}$ did not result in a decrease in cumulative ammonia losses from manure. At higher application levels of $580 \mathrm{~g} / \mathrm{d}$, LA has been reported to result in a $12 \%$ reduction in the rates of ammonia and nitrous oxide emissions from cattle manure relative to SA (Külling et al., 2002), although the graphical data did not seem to support the differences reported in tabulated form. Despite the apparent improvements in ruminal ammonia $\mathrm{N}$ metabolism to $\mathrm{CO}$, treatments applied in this experiment had no effect on the overall efficiency of utilization of dietary $\mathrm{N}$ for milk protein synthesis. Furthermore, the proportion of milk protein $\mathrm{N}$ originating from ruminal bacterial $\mathrm{N}$ was higher for the control than for LA and CO (by 23 and $17 \%$, respectively). Even though the proportion of bacterial $\mathrm{N}$ originating from ammonia $\mathrm{N}$ was comparable across treatments, data indicated that more bacterial (and most likely protozoal) $\mathrm{N}$ was apparently absorbed and utilized for milk protein synthesis on the control, consistent with the lower MNF to the duodenum for LA and CO. Current data are consistent with the view that the proportion of $\mathrm{MN}$ that is absorbed in the small intestine is the main variable determining the efficiency of utilization of ruminal ammonia $\mathrm{N}$ for milk protein synthesis (Hristov et al., 2003).

Both LA and CO treatments resulted in a numerical decrease in milk yield that probably reflects the nonsignificant reduction in DMI for these treatments relative to the control. Numerical (Faciola et al., 2005) or significant (Faciola et al., 2008; Hollmann and Beede, 2008) decreases in DMI and milk yield have been reported for lactating cows fed $\mathrm{CO}$ supplements that may reflect the negative effects of $\mathrm{CO}$ on diet palatability. Decreases in DMI have also been reported in lactating cows fed supplements of LA (Steele and Moore, 1968; Dohme et al., 2004), but not MA (Dohme et al., 2004; Odongo et al., 2007). The lack of an effect of MA on DMI suggests that the reduction in intake associated with $\mathrm{CO}$ is related to the effects of FA other than MA, with LA being the obvious candidate. Because treatments were administered into the rumen, intake was not significantly affected, but the numerically lower DMI for LA and $\mathrm{CO}$ is indicative that these FA may regulate intake through mechanisms other than reduced diet palatabil- ity. Some of the depression in DMI caused by ruminal LA administration may be explained by increases in molar propionate proportions and presumably ruminal propionate production (Allen, 2000), but this was not the case for CO.

Several experiments have indicated that under certain circumstances LA (Steele and Moore, 1968) or CO (Storry et al., 1971, 1974) in the diet can decrease mammary lipogenesis in lactating cows, but there was little evidence to suggest that $\mathrm{CO}$ or LA under the specified conditions of this experiment altered milk fat synthesis.

Ruminal administration of LA resulted in more than a 2-fold enrichment of LA in milk fat compared with the control. Increases in milk fat LA content were also accompanied by changes in the concentrations of other milk FA consistent with the findings of earlier experiments (Rindsig and Schultz, 1974; Dohme et al., 2004). Alterations in milk fat composition under these conditions can be considered as a consequence of LA replacing other FA during the synthesis of triacylglycerides in the mammary gland. Under most dietary conditions, LA secreted in milk is synthesized entirely de novo (refer to Shingfield et al., 2008c for review), but data from this experiment indicated that $18 \%$ of LA administered in the rumen was secreted in milk, consistent with previous studies reporting that 24 to $26 \%$ of LA added to the diet is recovered in milk fat (Rindsig and Schultz, 1974; Dohme et al., 2004). Dosing of LA into the rumen also increased the relative abundance and secretion of cis-9 12:1 in milk, providing further evidence that LA serves as a substrate for $\Delta^{9}$-desaturase in ruminant tissues (Shingfield et al., 2008b).

Administration of $\mathrm{CO}$ in the rumen resulted in 109 and $19.5 \%$ increases in milk LA and MA content, respectively, and reduced 6:0 to 10:0 concentrations relative to the control, confirming the results reported in earlier studies (Storry et al., 1971, 1974). Comprehensive analysis of milk FA composition also revealed that in addition to the established effects on short-chain FA and MCFA abundance, CO also enhanced milk fat trans 16:1 content and altered the relative distribution of trans 18:1 and CLA isomers. Changes in the abundance of specific trans $\mathrm{C} 18$ fatty acids can be attributed to ruminal metabolism of cis-9 $18: 1$ and $18: 2$ n-6 in CO, because metabolism of cis-9 18:1 is known to result in the formation of a several positional isomers of trans 18:1 in vitro (Mosley et al., 2002), whereas diets containing oils rich in 18:2 n-6 increase ruminal outflow of 18:1 and 18:2 biohydrogenation intermediates (Shingfield et al., 2008a).

The apparent transfer of LA from CO in the rumen into milk of $17 \%$ is in agreement with estimates for the LA treatment, whereas the apparent transfer of MA 
from the rumen into milk of $15 \%$ is much lower than a recovery of $39 \%$ reported previously (Dohme et al., 2004 ) but consistent with a value of $12 \%$ estimated from the data of Odongo et al. (2007). Even though it is difficult to reconcile the discrepancies between studies, both current and published results indicate that the transfer of LA and MA from the diet or rumen into milk is lower than the efficiency of incorporation of C18 FA into milk triacylglycerides in cows fed diets containing moderate amounts $(\leq 500 \mathrm{~g} / \mathrm{d})$ of lipid supplements (Glasser et al., 2008). Several factors may explain the implied lower transfer efficiency for MCFA compared with long-chain FA. Early studies demonstrated that up to $30 \%$ of LA in the diet can potentially be absorbed from the rumen (Hagemeister et al., 1979), whereas at high concentrations, it has been postulated that other MCFA may also be transported across the rumen wall or catabolized by bacteria adhered to rumen epithelium (Doreau and Ferlay, 1994). Indirect respiration calorimetry has also provided evidence to suggest that LA serves as a substrate for ATP synthesis in ruminant tissues, thus reducing availability for incorporation into milk fat (Dohme et al., 2004). Furthermore, a recent meta-analysis indicated that the mean digestibility of LA $(65 \%)$ and MA (72\%) in the small intestine of growing and lactating cattle was lower compared with C18 FA (74\%; Schmidely et al., 2008). It is also possible that the relatively low transfer is related to preferential incorporation of absorbed LA and MA into plasma phospholipids and cholesteryl esters that have a low affinity for mammary lipoprotein lipase (Olivecrona and Bengtsson-Olivecrona, 1987).

The potential impact of changes in milk FA composition to LA and $\mathrm{CO}$ on human health-related outcomes remain unclear. Clinical and epidemiological studies have provided a large body of data to indicate that when consumed in excess, LA, MA, and 16:0 in the human diet increase CVD risk and may also reduce insulin sensitivity, which is a key factor in the development of the metabolic syndrome (refer to Shingfield et al., 2008c for review). Consumption of foods containing MCFA are known to be associated with elevated plasma lowdensity lipoprotein-cholesterol concentrations in human subjects (Mensink and Katan, 1992), whereas national health policies advocate a population-wide reduction in the consumption of fat and saturated FA to reduce the incidence of chronic disease. However, establishing a clear role of a specific saturated FA on plasma lipid profiles within the overall context of intakes relevant to a given population remains challenging. This is due, at least in part, to human intervention studies reporting the effects of oils or fats on plasma lipids rather than a certain saturated FA per se, responses to a specific MCFA on CVD risk factors have often been examined at levels much higher than that consumed from the habitual diet, and also because inclusion of a specific saturated FA also alters the overall FA profile of the diet (Wilke and Clandinin, 2005).

Dairy fats, compared with polyunsaturated oils, have been shown (Cox et al., 1995; Hodson et al., 2001; Sjogren et al., 2004) to increase the concentration of HDL-cholesterol in plasma, which is inversely associated with the risk of heart disease in humans. This, along with emerging evidence that small particle, lowdensity lipoprotein cholesterol that is not influenced by saturated FA intake may be an important component in the development of CVD (Sjogren et al., 2004), has prompted a re-evaluation of nutritional recommendations with respect to dairy fat consumption (German et al., 2009). Furthermore, comparisons of diets supplying 0.6 or $1.2 \%$ of dietary energy as MA indicated that at moderate levels, increases in MA intake were associated with significant decreases in plasma triacylglycerides, increases in HDL-cholesterol and significant enrichment of 20:5 n-3 and 22:6 n-6 in plasma phospholipids in healthy men (Dabadie et al., 2005). Lauric acid may also exert a specific effect on HDL-cholesterol; a metaanalysis of 60 human subject trials concluded that LA had a more favorable effect on the total:HDL-cholesterol ratio than any other FA studied, either saturated or unsaturated (Mensink et al., 2003). Lauric acid is also known to exhibit an array of antiprotozoal, antifungal, antibacterial, and antiviral activities (Kabara, 1978; Enig, 1998) and inhibit the growth of certain cancer cell lines (Salerno and Smith, 1991; Welsch, 1992; Lima et al., 2002).

A recent evaluation concluded that despite of the major contribution of milk and dairy products to saturated FA in the human diet, there is no clear relationship between the consumption of these foods and CVD risk (German et al., 2009). Furthermore, based on benefits to human health, it has been proposed that oils rich in LA should be made more readily available in the US food supply chain (Enig, 1998). Natural enrichment of LA in ruminant milk represents a means to increase LA intakes in human populations, with the potential to improve long-term human health.

\section{CONCLUSIONS}

This study confirmed the potent antiprotozoal properties of LA and CO when dosed intraruminally. Ruminal ammonia concentration was also significantly reduced by both treatments and $\mathrm{CO}$ reduced urinary $\mathrm{N}$ losses and methane production in the rumen of lactating dairy cows. Both treatments resulted in marginal decreases in DMI that may account for a numerical reduction in ruminal microbial protein synthesis. Intraruminal 
administration of LA and CO enhanced milk fat 12:0, cis-9 12:1, and trans-9 12:1 content and decreased shortchain, C16, and C18 fatty acid concentrations. Natural enrichment of LA in ruminant milk offers one approach to increase LA intake in human populations with the potential to improve long-term human health.

\section{ACKNOWLEDGMENTS}

This study was supported by funds from the Idaho Dairymen Association and University of Idaho Agricultural Experiment Station. The authors thank V. Borek (Department of Plant, Soil, and Entomological Sciences, University of Idaho) for conducting the methane analyses, W. Price (Statistical Programs, College of Agricultural and Life Sciences, University of Idaho) for assistance with statistical evaluation of the results, and the staff of the Department of Animal and Veterinary Science Dairy Center for their conscientious care of the experimental cows.

\section{REFERENCES}

Ajisaka, N., N. Mohammed, K. Hara, K. Mikuni, K. Hara, H Hashimoto, T. Kumata, S. Kanda, and H. Itabashi. 2002. Effects of medium-chain fatty acid-cyclodextrin complexes on ruminal methane production in vitro. Anim. Sci. J. 73:479-484.

Allen, M. S. 2000. Effects of diet on short-term regulation of feed intake by lactating dairy cattle. J. Dairy Sci. 83:1598-1624.

APHA. 1998. Standard Methods for the Examination of Water and Wastewater. 20th ed. S. C. Lenore, A. E. Greenberg, and A. D. Eaton, ed. American Public Health Association, Washington, DC.

AOAC. 2000. Official Methods of Analysis. 17th ed. Association of Official Analytical Chemists, Arlington, VA.

Blaxter, K. L., and J. Czerkawski. 1966. Modifications of the methane production of the sheep by supplementation of its diet. J. Sci. Food Agric. 17:417-421.

Broderick, G. A., and N. R. Merchen. 1992. Markers for quantifying microbial protein synthesis in the rumen. J. Dairy Sci. 75:26182632.

Bussink, D. W., and O. Oenema. 1998. Ammonia volatilization from dairy farming systems in temperate areas: A review. Nutr. Cycl. Agroecosyst. 51:19-33.

Chen, X. B. 1989. Excretion of purine derivatives by sheep and cattle and its use for estimation of absorbed microbial protein. $\mathrm{PhD}$ Thesis, University of Aberdeen, UK.

Chen, X. B., Y. K. Chen, M. F. Franklin, E. R. Ørskov, and W. J. Shand. 1992. The effect of feed intake and body weight on purine derivative excretion and microbial protein supply in sheep. J. Anim. Sci. 70:1534-1542.

Christie, W. W. 1982. A simple procedure for rapid transmethylation of glycerolipids and cholesteryl esters. J. Lipid Res. 23:10721075 .

Coleman, G. S. 1979. The role of rumen protozoa in the metabolism of ruminants given tropical feeds. Trop. Anim. Prod. 4:199-212.

Cox, C., J. Mann, W. Sutherland, A. Chisholm, and M. Skeaff 1995. Effects of coconut oil, butter, and safflower oil on lipid and lipoproteins in persons with moderately elevated cholesterol levels. J. Lipid Res. 36:1787-1795.

Craske, J. D., and C. D. Bannon. 1988. Letter to the editor. J. Am. Oil Chem. Soc. 65:1190-1191.
CRC. 1988. CRC Handbook of Chemistry and Physics. 69th ed. R. C. Weast, M. J. Astle, and W. H. Beyer, ed. CRC Press Inc., Boca Raton, FL.

Dabadie, H., E. Peuchant, M. Bernard, P. LeRuyet, and F. Mendy. 2005. Moderate intake of myristic acid in sn-2 position has beneficial lipidic effects and enhances DHA of cholesteryl esters in an interventional study. J. Nutr. Biochem. 16:375-382.

Dehority, B. A. 1993. Laboratory Manual for Classification and Morphology of Rumen Ciliate Protozoa. CRC Press Inc., Boca Raton, FL.

Delmonte, P., A. Kataok, B. A. Corl, D. E. Bauman, and M. P Yurawecz. 2005. Relative retention order of all isomers of cis/trans conjugated linoleic acid FAME from the 6,8- to 13,15-positions using silver ion HPLC with two elution systems. Lipids 40:509514.

Dohme, F., A. Machmüller, B. L. Estermann, P. Pfister, A. Wasserfallen, and M. Kreuzer. 1999. The role of the rumen ciliate protozoa for methane suppression caused by coconut oil. Lett. Appl. Microbiol. 29:187-192.

Dohme, F., A. Machmüller, F. Sutter, and M. Kreuzer. 2004. Digestive and metabolic utilization of lauric, myristic and stearic acid in cows, and associated effects on milk fat quality. Arch. Anim. Nutr. 58:99-116.

Dohme, F., A. Machmüller, A. Wasserfallen, and M. Kreuzer. 2001 Ruminal methanogenesis as influenced by individual fatty acids supplemented to complete ruminant diets. Lett. Appl. Microbiol. $32: 47-51$.

Dong, Y., H. D. Bae, T. A. McAllister, G. W. Mathison, and K. J. Cheng. 1997. Lipid-induced depression of methane production and digestibility in the artificial rumen system (RUSITEC). Can. J. Anim. Sci. 77:269-278.

Doreau, M., and A. Ferlay. 1994. Digestion and utilisation of fatty acids by ruminants. Anim. Feed Sci. Technol. 45:379-396.

Enig, M. G. 1998. Lauric oils as antimicrobial agents: Theory of effect, scientific rationale, and dietary applications as adjunct nutritional support for HIV-infected individuals. Nutrients and Foods in AIDS. R. R. Watson ed. CRC Press, Boca Raton, FL.

Faciola, A. P., G. A. Broderick, A. N. Hristov, and M. I. Leão 2004. Effect of two forms of lauric acid on ruminal protozoa and fermentation pattern in dairy cows. J. Dairy Sci. 87(Suppl. 1):53. (Abstr.)

Faciola, A. P., G. A. Broderick, A. N. Hristov, and M. I. Leão. 2005 Effect of feeding different levels of lauric acid on ruminal protozoa, and milk production in dairy cows. J. Dairy Sci. 88(Suppl. 1):178. (Abstr.)

Faciola, A. P., G. A. Broderick, A. N. Hristov, and J. A. Pires. 2008. Effect of four levels of lauric acid on ruminal protozoa, milk production and composition in dairy cows. J. Dairy Sci. 91(Suppl. 1):76. (Abstr.)

Foley, A. E., A. N. Hristov, A. Melgar, J. K. Ropp, R. P. Etter, S. Zaman, C. W. Hunt, K. Huber, and W. J. Price. 2006. Effect of barley and its amylopectin content on ruminal fermentation and nitrogen utilization in lactating dairy cows. J. Dairy Sci. 89:4321-4335.

German, J. B., R. A. Gibson, R. M. Krauss, P. N. Benoît Lamarche, W. A. van Staveren, J. M. Steijns, L. C. P. G. M. de Groot, A. L. Lock, and F. Destaillats. 2009. A reappraisal of the impact of dairy foods and milk fat on cardiovascular disease risk. Eur. J. Nutr. 48:191-203.

Glasser, F., M. Doreau, A. Ferlay, and Y. Chilliard. 2007. Technical note: Estimation of milk fatty acid yield from milk fat data. J. Dairy Sci. 90:2302-2304.

Glasser, F., A. Ferlay, M. Doreau, P. Schmidely, D. Sauvant, and Y. Chilliard. 2008. Long-chain fatty acid metabolism in dairy cows: A meta-analysis of milk fatty acid yield in relation to duodenal flows and de novo synthesis. J. Dairy Sci. 91:2771-2785.

Hagemeister, H., W. Kaufmann, and A. Wiechen. 1979. Determination of the resorption sites of fatty acids in the digestive tract of dairy cows. Kieler Milchw. Forsch. 31:5-10.

Henderson, C. 1973. The effects of fatty acids on pure cultures of rumen bacteria. J. Agric. Sci. 81:107-112. 
Hodson, L., C. M. Skeaff, and W. A. Chisholm. 2001. The effect of replacing dietary saturated fat with polyunsaturated or monounsaturated fat on plasma lipids in free-living young adults. Eur. J. Clin. Nutr. 55:908-915.

Hollmann, M., and D. K. Beede. 2008. Dietary coconut oil and animal fat blend decrease lactational performance of Holstein cows fed a high starch diet. J. Dairy Sci. 91(Suppl. 1):331.

Hristov, A. N. 2007. Comparative characterization of reticular and duodenal digesta and possibilities to estimate microbial outflow from the rumen based on reticular sampling in dairy cows. J. Anim. Sci. 85:2606-2613.

Hristov, A. N., and G. Broderick. 1996. Synthesis of microbial protein in ruminally cannulated cows fed alfalfa silage, alfalfa hay or corn silage. J. Dairy Sci. 79:1627-1637.

Hristov, A. N., K. L. Grandeen, J. K. Ropp, and M. A. McGuire. 2004b. Effect of sodium laurate on ruminal fermentation and utilization of ruminal ammonia nitrogen for milk protein synthesis in dairy cows. J. Dairy Sci. 87:1820-1831.

Hristov, A. N., M. Ivan, and T. A. McAllister. 2004a. In vitro effects of individual fatty acids on protozoal numbers and on fermentation products in ruminal fluid from cattle fed a high concentrate, barley-based diet. J. Anim. Sci. 82:2693-2704.

Hristov, A. N., M. Ivan, L. M. Rode, and T. A. McAllister. 2001. Fermentation characteristics and ruminal ciliate protozoal populations in cattle fed medium- or high-concentrate barleybased diets. J. Anim. Sci. 79:515-524.

Hristov, A. N., and J.-P. Jouany. 2005. Factors affecting the efficiency of nitrogen utilization in the rumen. Pages 117-166 in Nitrogen and Phosphorus Nutrition of Cattle and Environment. A. N. Hristov and E. Pfeffer, ed. CAB International, Wallingford, UK.

Hristov, A. N., T. A. McAllister, and K.-J. Cheng. 1998. Effect of dietary or abomasal supplementation of exogenous polysaccharidedegrading enzymes on rumen fermentation and nutrient digestibility. J. Anim. Sci. 76:3146-3156.

Hristov, A. N., T. A. McAllister, F. H. Van Herk, K.-J. Cheng, C. J. Newbold, and P. R. Cheeke. 1999. Effect of Yucca schidigera on ruminal fermentation and nutrient digestion in heifers. J. Anim. Sci. $77: 2554-2563$.

Hristov, A. N., and J. K. Ropp. 2003. Effect of dietary carbohydrate composition and availability on utilization of ruminal ammonia nitrogen for milk protein synthesis in dairy cows. J. Dairy Sci. $86: 2416-2427$.

Hristov, A. N., J. K. Ropp, K. L. Grandeen, S. Abedi, R. P. Etter, A. Melgar, and A. E. Foley. 2005. Effect of carbohydrate source on ammonia utilization in lactating dairy cows. J. Anim. Sci. 83:408-421.

Hristov, A. N., J. K. Ropp, K. L. Grandeen, R. P. Etter, A. Foley, A. Melgar, and W. Price. 2003. Efficiency of utilization of ruminal ammonia $\mathrm{N}$ for milk protein synthesis in dairy cows. Pages 601604 in Progress in Research on Energy and Protein Metabolism, EAAP publication No. 109, W. B. Souffrant and C. C. Metges, ed., Wageningen Academic Publishers, Wageningen, the Netherlands.

IDF. 1987. Milk-Determination of fat content -Gravimetric method (Röse Gottlieb reference method)-International Standard IDF-1C and Cream-Determination of fat content -Gravimetric method (Röse Gottlieb reference method)-International Standard IDF16C. International Dairy Federation, Brussels, Belgium.

Jenkins, T. C., and M. A. McGuire. 2006. Major advances in nutrition: Impact on milk composition. J. Dairy Sci. 89:1302-1310.

Johnson, K. A., M. T. Huyler, H. H. Westberg, B. K. Lamb, and P. Zimmerman. 1994. Measurement of methane emissions from ruminant livestock using a $\mathrm{SF}_{6}$ tracer technique. Environ. Sci. Technol. 28:359-362.

Jordan, E., D. K. Lovett, F. J. Monahan, J. Callan, B. Flynn, and F. P. O'Mara. 2006. Effect of refined coconut oil or copra meal on methane output and on intake and performance of beef heifers. J. Anim. Sci. 84:162-170.

Jouany, J. P. 1996. Effect of rumen protozoa on nitrogen utilization by ruminants. J. Nutr. 126:1335S-1346S.
Kabara, J. J. 1978. Fatty acids and derivatives as antimicrobial agents - A review. The Pharmacological Effect of Lipids, J. J. Kabara, ed. American Oil Chemists' Society, Champaign, IL.

Karnati, S. K. R., J. T. Sylvester, C. V. D. M. Ribeiro, L. E. Gilligan, and J. L. Firkins. 2009a. Investigating unsaturated fat, monensin, or bromoethanesulfonate in continuous cultures retaining ruminal protozoa. I. Fermentation, biohydrogenation, and microbial protein synthesis. J. Dairy Sci. 92:3849-3860.

Karnati, S. K. R., Z. Yu, and J. L. Firkins. 2009b. Investigating unsaturated fat, monensin, or bromoethanesulfonate in continuous cultures retaining ruminal protozoa. II. Interaction of treatment and presence of protozoa on prokaryotic communities. J. Dairy Sci. 92:3861-3873.

Külling, D. R., F. Dohme, H. Menzi, F. Sutter, P. Lischer, and M. Kreuzer. 2002. Methane emissions of differently fed dairy cows and corresponding methane and nitrogen emissions from their manure during storage. Environ. Monit. Assess. 79:129-150.

Lane, D. J. 1991. 16S/23S rRNA sequencing. Pages 115-175 in Nucleic Acid Techniques in Bacterial Systematics, E. Stackebrandt and M.D. Goodfellow, eds. John Wiley, and Sons, New York, NY, USA.

Lima, T. M., C. C. Kanunfre, C. Pompeia, R. Verlengia, and R. Curi. 2002. Ranking the toxicity of fatty acids on Jurkat and Raji cells by flow cytometric analysis. Toxicol. In Vitro 16:741-747.

Machmüler, A., and M. Kreuzer. 1999. Methane suppression by coconut oil and associated effects on nutrient and energy balance in sheep. Can. J. Anim. Sci. 79:65-72.

Machmüller, A. 2006. Medium-chain fatty acids and their potential to reduce methanogenesis in domestic ruminants. Agric. Ecosyst. Environ. 112:107-114.

Machmüller, A., C. R. Soliva, and M. Kreuzer. 2002. In vitro ruminal methane suppression by lauric acid as influenced by dietary calcium. Can. J. Anim. Sci. 8:233-239.

Machmüller, A., C. R. Soliva, and M. Kreuzer. 2003. Methanesuppressing effect of myristic acid in sheep as affected by dietary calcium and forage proportion. Br. J. Nutr. 90:529-540.

McCleary, B. V., V. Solah, and T. S. Gibson. 1994. Quantitative measurement of total starch in cereal flours and products. J. Cereal Sci. 20:51-58.

McDougall, E. I. 1948. The composition and output of sheep's saliva. Biochem. J. 43:99-109.

Mensink, R. P., and M. B. Katan. 1992. Effect of dietary fatty acids on serum lipids and lipoproteins. A meta-analysis of 27 trials. Arterioscler. Thromb. 12:911-919.

Mensink, R. P., P. L. Zock, A. D. M. Kester, and M. B. Katan. 2003. Effects of dietary fatty acids and carbohydrates on the ratio of serum total to HDL cholesterol and on serum lipids and apolipoproteins: A meta-analysis of 60 controlled trials. Am. J. Clin. Nutr. 77:1146-1155.

Misselbrook, T. H., J. M. Powell, G. A. Broderick, and J. H. Grabber. 2005. Dietary manipulation in dairy cattle: Laboratory experiments to assess the influence of ammonia emissions. J. Dairy Sci. $88: 1765-1777$.

Mosley, E. E., G. L. Powell, M. B. Riley, and T. C. Jenkins. 2002. Microbial biohydrogenation of oleic acid to trans isomers in vitro. J. Lipid Res. 43:290-296.

Nagaraja, T. G., C. J. Newbold, C. J. Van Nevel, and D. I. Demeyer. 1997. Manipulation of ruminal fermentation. Pages 523-623 in the Rumen Microbial Ecosystem. P. N. Hobson and C. S. Stewart, ed. Blackie Academic and Professional, London, UK.

Ndegwa, P. M., A. N. Hristov, J. Arogo, and R. E. Sheffield. 2008. A review of ammonia emissions mitigation techniques for concentrated animal feeding operations. Biosystems Eng. 100:453-469.

Ndegwa, P. M., V. K. Vaddella, A. N. Hristov, and H. S. Joo. 2009. Measuring concentrations of ammonia in ambient air or exhaust air stream using acid traps. J. Environ. Qual. 38:647-653.

National Research Council. 2001. Nutrient Requirements of Dairy Cattle. 7th rev. ed. National Academy Press, Washington, DC.

Odongo, N. E., M. M. Or-Rashid, E. Kebreab, J. France, and B. W. McBride. 2007. Effect of supplementing myristic acid in dairy cow 
rations on ruminal methanogenesis and fatty acid profile in milk. J. Dairy Sci. 90:1851-1858.

Oldick, B. S., J. L. Firkins, and N. R. St-Pierre. 1999. Estimation of microbial nitrogen flow to the duodenum of cattle based on dry matter intake and diet composition. J. Dairy Sci. 82:1497-1511.

Olivecrona, T., and G. Bengtsson-Olivecrona. 1987. Lipoprotein lipase from milk-The model enzyme in lipoprotein lipase research. Pages 15-58 in Lipoprotein Lipase. J. Borensztajn, ed. Evener, Chicago, IL.

Palmquist, D. L., and T. C. Jenkins. 1980. Fat in lactation rations: Review. J. Dairy Sci. 63:1-14

Raskin, L., J. M. Stromley, B. E. Rittmann, and D. A. Stahl. 1994 Group-specific $16 \mathrm{~S}$ rRNA hybridization probes to describe natural communities of methanogens. Appl. Environ. Microbiol. 60:12321240 .

Rindsig, R. B., and L. H. Schultz. 1974. Effect of feeding lauric acid to lactating cows on milk composition, rumen fermentation, and blood lipids. J. Dairy Sci. 57:1414-1419.

Salerno, J. W., and D. E. Smith. 1991. The use of sesame oil and other vegetable oils in the inhibition of human colon cancer growth in vitro. Anticancer Res. 11:209-215.

Schmidely, D., F. Glasser, M. Doreau, and D. Sauvant. 2008. Digestion of fatty acids in ruminants: A meta-analysis of flows and variation factors. 1. Total fatty acids. Animal 2:677-690.

Sharp, R., C. J. Ziemer, M. D. Stern, and D. A. Stahl. 1998. Taxon specific association between protozoal and methanogen populations in the rumen and a model rumen system. FEMS Microbiol. Ecol. $26: 71-78$

Shi, Y., D. B. Parker, N. A. Cole, B. W. Auvermann, and J. E. Mehlhorn. 2001. Surface amendments to minimize ammonia emissions from beef cattle feedlots. Trans. ASAE 44:677-682.

Shingfield, K. J., S. Ahvenjärvi, V. Toivonen, A. Ärölä, K. V. V. Nurmela, P. Huhtanen, and J. M. Griinari. 2003. Effect of fish oil on biohydrogenation of fatty acids and milk fatty acid content in cows. Anim. Sci. 77:165-179.

Shingfield, K. J., S. Ahvenjärvi, V. Toivonen, A. Vanhatalo, P. Huhtanen, and J. M. Griinari. 2008a. Effect of incremental levels of sunflower-seed oil in the diet on ruminal lipid metabolism in lactating cows. Br. J. Nutr. 99:971-983.

Shingfield, K. J., A. Ärölä, S. Ahvenjärvi, A. Vanhatalo, V. Toivonen, J. M. Griinari, and P. Huhtanen. 2008b. Ruminal infusions of CobaltEDTA reduce mammary $\Delta$-desaturase index and alter milk fatty acid composition in lactating cows. J. Nutr. 138:710-717.

Shingfield, K. J., Y. Chilliard, V. Toivonen, P. Kairenius, and D. I. Givens. 2008c. Trans fatty acids and bioactive lipids in ruminant milk. Pages 3-65 in Bioactive Components of Milk, Advances in Experimental Medicine and Biology, Vol. 606, Z. Bösze, ed. Springer, New York, NY.

Shingfield, K. J., C. K. Reynolds, G. Hervás, J. M. Griinari, A. S. Grandison, and D. E. Beever. 2006. Examination of the persistency of milk fatty acid composition responses to fish oil and sunflower oil in the diet of dairy cows. J. Dairy Sci. 89:714-732.

Shingfield, K. J., C. K. Reynolds, B. Lupoli, V. Toivonen, M. P. Yurawecz, P. Delmonte, J. M. Griinari, A. S. Grandison, and D. E. Beever. 2005. Effect of forage type and proportion of concentrate in the diet on milk fatty acid composition in cows fed sunflower oil and fish oil. Anim. Sci. 80:225-238.

Sjogren, P., M. Rosell, C. Skoglund-Andersson, S. Zdrakovic, B. Vessby, and U. de Faire. 2004. Milk-derived fatty acids are associated with a more favorable LDL particle size distribution in healthy men. J. Nutr. 34:1729-1735.

Soliva, C. R., I. K. Hindrichsen, L. Meile, M. Kreuzer, and A. Machmüller. 2003. Effects of mixtures of lauric and myristic acid on rumen methanogens and methanogenesis in vitro. Lett. Appl. Microbiol. 37:35-39.

Soliva, C. R., L. Meile, A. Cieślak, M. Kreuzer, and A. Machmüller. 2004. Rumen simulation technique study on the interactions of dietary lauric and myristic acid supplementation in suppressing ruminal methanogenesis. Br. J. Nutr. 92:689-700.
Steele, W., and J. H. Moore. 1968. The effects of a series of saturated fatty acids in the diet on milk-fat secretion in the cow. J. Dairy Res. 35:361-370.

Storry, J. E., P. E. Brumby, A. J. Hall, and V. W. Johnson. 1974. Response of the lactating cow to different methods of incorporating casein and coconut oil in the diet. J. Dairy Sci. 57:61-67.

Storry, J. E., A. J. Hall, and V. W. Johnson. 1971. The effects of increasing amounts of dietary coconut oil on milk-fat secretion in the cow. J. Dairy Res. 38:73-77.

Sutton, J. D., R. Knight, A. B. McAllan, and R. H. Smith. 1983. Digestion and synthesis in the rumen of sheep given diets supplemented with free and protected oils. Br. J. Nutr. 49:419432.

Sylvester, J. T., S. K. R. Karnati, Z. Yu, C. J. Newbold, and J. L. Firkins. 2005. Evaluation of a real-time PCR assay quantifying the ruminal pool size and duodenal flow of protozoal nitrogen. J. Dairy Sci. 88:2083-2095.

Udén, P., P. E. Colucci, and P. J. Van Soest. 1980. Investigation of chromium, cerium, and cobalt as markers in digesta. Rate of passage studies. J. Sci. Food Agric. 31:625-632.

Ulberth, F., R. G. Gabernig, and F. Schrammel. 1999. Flame-ionization detector response to methyl, ethyl, propyl, and butyl esters of fatty acids. J. Am. Oil Chem. Soc. 76:263-266.

Valadares, R. F. D., G. A. Broderick, S. C. Valadares Filho, and M. K. Clayton. 1999. Effect of replacing alfalfa silage with high moisture corn on ruminal protein synthesis estimated from excretion of total purine derivatives. J. Dairy Sci. 82:2686-2696.

Van Keulen, J., and B. A. Young. 1977. Evaluation of acid-insoluble ash as a natural marker in ruminant digestibility studies. J. Anim. Sci. $44: 282-287$.

Van Soest, P. J., J. B. Robertson, and B. A. Lewis. 1991. Methods for dietary fiber, neutral detergent fiber, and nonstarch polysaccharides in relation to animal nutrition. J. Dairy Sci. 74:3583-3597.

Vander Pol, M., A. N. Hristov, S. Zaman, and N. Delano. 2007. Peas can replace soybean meal and corn grain in dairy cow diets. J. Dairy Sci. 91:698-703.

Vander Pol, M., A. N. Hristov, S. Zaman, N. Delano, and C. Schneider. 2008. Effect of inclusion of peas in dairy cow diets on ruminal fermentation, digestibility, and nitrogen losses. Anim. Feed Sci Technol. 150:95-105.

Verbic, J., X. B. Chen, N. A. Macleod, and E. R. Ørskov. 1990. Excretion of purine derivatives by ruminants: Effect of microbial nucleic acid infusion on purine derivative excretion by steers. J. Agric. Sci. 114:243-248.

Welsch, C. W. 1992. Dietary fat, calories, and mammary gland tumorogenesis. Adv. Exp. Med. Biol. 322:203-222.

Wilke, M. S., and M. T. Clandinin. 2005. Influence of dietary saturated fatty acids on the regulation of plasma cholesterol concentration. Lipids 40:1207-1213.

Williams, A. G., and G. S. Coleman. 1992. The Rumen Protozoa. Springer-Verlag, New York, NY.

Williams, A. G., and G. S. Coleman. 1997. The rumen protozoa. Pages 73-139 in the Rumen Microbial Ecosystem. P. N. Hobson and C. S. Stewart, ed. Blackie Academic and Professional, London, UK.

Williams, Y. J., S. Popovski, S. M. Rea, L. C. Skillman, A. F. Toovey, K. S. Northwood, and A. D. Wright. 2009. A vaccine against rumen methanogens can alter the composition of archaeal populations. Appl. Environ. Microbiol. 75:1860-1866.

Wolin, M. J., and T. L. Miller. 1988. Microbe-microbe interactions. Page 527 in The Rumen Microbial Ecosystem. P. N. Hobson, ed. Elsevier Scientific Publishers, London, UK.

Yabuuchi, Y., Y. Matsushita, H. Otsuka, K. Fukamachi, and Y. Kobayashi. 2006. Effects of supplemental lauric acid-rich oils in high-grain diet on in vitro rumen fermentation. Anim. Sci. J. 77:300-307.

Yu, Z., and M. Morrison. 2004. Comparisons of different hypervariable regions of $r$ rs genes for use in fingerprinting of microbial communities by PCR-denaturing gradient gel electrophoresis. Appl. Environ. Microbiol. 70:4800-4806. 